Article

\title{
Analysis of Symmetrical/Asymmetrical Loading Influence of the Full-Suspension Downhill Bicycle's Frame on the Crack Failure Formation at a Critical Point during Different Driving Scenarios and Design Improvement
}

\author{
Vladimír Bulej $^{1, * \mathbb{D}}$, Ivan Kuric ${ }^{1}$, Milan Sága ${ }^{2} \mathbb{D}$, Milan Vaško ${ }^{2} \mathbb{D}$, Zuzana Ságová ${ }^{1}$, Michal Bartoš ${ }^{1} \mathbb{D}$ \\ and Stanislaw Legutko ${ }^{3}$ (D)
}

1 Department of Automation and Production Systems, Faculty of Mechanical Engineering, University of Žilina, Univerzitna 8215/1, 01026 Zilina, Slovakia; ivan.kuric@fstroj.uniza.sk (I.K.); zuzana.sagova@fstroj.uniza.sk (Z.S.); michal.bartos@fstroj.uniza.sk (M.B.)

2 Department of Applied Mechanics, Faculty of Mechanical Engineering, University of Žilina, Univerzitna 8215/1, 01026 Zilina, Slovakia; milan.saga@fstroj.uniza.sk (M.S.); milan.vasko@fstroj.uniza.sk (M.V.)

3 Institute of Mechanical Technology, Faculty of Mechanical Engineering, Poznan University of Technology, 3 Piotrowo Street, 60-965 Poznan, Poland; stanislaw.legutko@put.poznan.pl

* Correspondence: vladimir.bulej@fstroj.uniza.sk; Tel.: +421-41-513-2811

check for updates

Citation: Bulej, V.; Kuric, I.; Sága, M.; Vaško, M.; Ságová, Z.; Bartoš, M.;

Legutko, S. Analysis of

Symmetrical/Asymmetrical Loading Influence of the Full-Suspension Downhill Bicycle's Frame on the Crack Failure Formation at a Critical Point during Different Driving Scenarios and Design Improvement. Symmetry 2022, 14, 255. https:// doi.org/10.3390/sym14020255

Academic Editor:

Kateryna Kravchenko

Received: 1 November 2021

Accepted: 8 January 2022

Published: 28 January 2022

Publisher's Note: MDPI stays neutral with regard to jurisdictional claims in published maps and institutional affiliations.

Copyright: (C) 2022 by the authors. Licensee MDPI, Basel, Switzerland. This article is an open access article distributed under the terms and conditions of the Creative Commons Attribution (CC BY) license (https:// creativecommons.org/licenses/by/ $4.0 /)$.

\begin{abstract}
The article deals with the analysis of the existing full-suspension downhill bicycle's frame damaged while using and the subsequent conceptual improved design of the critical point. The origin of symmetrical and asymmetrical bicycle loads in individual riding modes is investigated. Subsequently, their impact on the overall load of the frame and especially the identified critical point are assessed. An overview of different full-suspension bicycle frames, complemented by a literature overview of research related to cycling engineering and sport application is introduced. The first phase began with a kinematic analysis of the bicycle suspension system and an effect assessment of the symmetrical or asymmetrical distribution of forces, respectively, in the individual components. Furthermore, a strength analysis of the main frame was performed, taking into account the static and dynamic forces. Based on the results of the analyses performed in the ANSYS/Workbench, a critical frame point, as well as the role of individual driving regimes, were identified. The structural detail of the pocket under the saddle tube together with the asymmetrical combined load generated while out of saddle pedalling proved to be crucial for frame crack initiation and formation. Different design variants with improved stiffness were proposed for the given place. The chosen variant can be successfully implemented due to the final reduction of the maximum stress level approximately two times compared to the original pocket (only $50.4 \%$ of the original maximum stress) as well as a simple design and repair of the damaged area in terms of technology.
\end{abstract}

Keywords: full suspension bike frame; case study; conceptual design; static structural analysis; stress analysis; bicycle frame analysis; critical point improvement

\section{Introduction}

In recent years, biking has become an increasingly common relaxation activity and sport. Its popularity has increased even more in 2020 due to the difficult conditions of the coronavirus pandemic in which the collective sports are subjected to strong restrictions so individual sports present an alternative. The modern bicycle consists of a frame equipped with other components including handle-bars, brakes, wheels, pedals, and gears, in various configurations for different modes of cycling. Atkinson et al. [1], Bartoš [2], Macdermid et al. [3] and others mentioned that in general there are three main objectives in cycling science: 
- To optimize the technical equipment (the bicycle itself and its mechanical properties, suspension, frame, material base, kinematics; wearing, ventilation and thermal regulation; safety elements, etc.) to reach the highest possible performance, total efficiency, and safety [2-17];

- To identify the various human factors (human body parameters and genetic predictions), environmental factors (terrain, temperature, humidity, sunlight, wind), other external factors (for instance cycling nutrition) that have a significant influence on cycling power output or velocity, and, often, complex interrelationships between these factors [1,18-21];

- To suggest future directions for research to help clarify how cycling performance can be optimized, given different race disciplines, environments and riders, application of progressive technologies, etc., [22-26].

Nowadays, there is strong research being conducted in areas related to cycloengineering, e.g., in designing new frames [4,5], suspension mechanism components [6,7], stiffness analysis [8-11], kinematic and dynamic analysis [12-15], material/technology development $[8,16,17]$, study the relationship between the bicycle and the cyclist's body $[18,19]$ as well as safety analysis and improvement $[19,20]$. These topics are also related to other general areas such as medicine and healthcare, material science, aerodynamics, green energies, additive technologies, etc.

The mechanical properties of a final bicycle can be considered as one of the key factors that influence sports results for the discipline of mountain-bike design [4-17]. Some design concepts for bicycle frames can significantly increase fatigue safety and rigid performance. Cheng et al. [4] oriented their study on stress analysis, fatigue testing and simulation, improving the safety factor, as well as the weight of on-road bicycle frame via simulation results from ANSYS/Workbench software. The main advantage of these simulations is that fatigue safety and bicycle performance can be predicted and estimated during the design phase which can have a significantly positive influence on cost reduction in the production phase. Covill et al. [9] determined the static FEM analysis of standard steel bicycle frames under a range of loads and under different conditions. Outlined in [10] there is an FEM model using beam elements to represent a road bicycle frame under two standard loading conditions to understand the vertical compliance and lateral stiffness characteristics of 82 existing bicycle frames from the bicycle's geometry. Other authors, e.g., Gupta and Rao [11], studied the stress distribution and deformations in a mountain bicycle frame under steady-state pedalling including horizontal and vertical impacts. As Liu et al. [12] mentioned, the total stiffness and final performance were significantly influenced not only by the main frame, but also the frontal/rear shock absorber as a quality of the welded joints production. Their failure can bring serious injuries to the cyclist. Virgala et al. [13] and Kelemen et al. [14], respectively, address their research on kinematics performance and the strength analysis of designed mechanisms. Other authors, e.g., Redfield [15], deal with bond graph modeling of a mountain bike (mainly for hard-tail bikes) and the rider in order to obtain a baseline prediction for bicycle properties. Computer simulation is a very strong tool for bicycle designers [16,17]; however, Atkinson [1] and others have pointed out that the application of different sensors (bicycle-mounted strain gauges) directly on a bike during the races is starting to play a significant role as well. This approach can provide verification of the simulation results with real data.

In recent years, several other development trends have been visible that affect the mechanical properties, dimensioning, and utility values of bicycles such as using electric bicycles, modern production technologies, and control methods. During the last five years, the popularity of electro-bicycles, also known as e-bikes, has increased dramatically and their prevalence among non-professional users has increased as well. This kind of bicycle has some specific characteristics, e.g., different mass, forces and torques distribution, total weight. Thus, there is expected to be increasing scientific interest in this area as well. Xiao et al. [5] applied the topology optimization methods to generate robust electric bicycle main frames by optimizing the material distribution subject to the constraints and dynamic 
loads. The role and usage of progressive production technologies and equipment are constantly increasing every year regarding the cheaper and faster production of new, often advanced shaped parts. In the last few years, many so-called additive techniques have reached the quality and parameters (stiffness, precision, etc.) required for real application in vehicle design [22]. Sniehotta [23] deals with the possibility of using 3D printing to produce belt wheels and other parts of bikes. In order to achieve the required strength and other technical parameters, it is essential that key structural elements are correctly designed but also correctly manufactured. This can be verified by a quality check. One of the innovative approaches consists of combining robotic arm-based measurements with 3D geometry mathematical models for bicycle frames, a quality check described by Lin 2019 et al. [25].

The dumping of bicycle vibrations excited while driving (mainly in rough terrain) can be considered as the second priority in research focused on bicycle design. A series of studies with both numerical simulation and small laboratory experimental models of bio-inspired features, for instance, dumpers, have been conducted by Yang et al. [26] The results are promising because they improved vibration reduction performance of suspension system for cyclo-design over traditional passive systems. Zuraulis et al. [21] investigated the impact of road roughness on the duration of contact between the vehicle (car, motorbike, bike) wheel and a road surface.

Finally, as was mentioned above, the cyclo-design is related not only to the mechanical properties of the bicycles but also to human body kinematics and medicine. Research on the medical aspects of cycling focuses on several goals. Chacon-Murguia et al. [18] proposed a method for human gait and leg motion kinematic analysis via a study of camera records. The investigation of the locomotion of multibody moving systems was aimed at by authors like Virgala et al. [13] and Macdermid [3]. Mellion, et al. looked at the relationship between cycling and medicine aspects in a more detailed article [19]. The work of Liu et al. [6] where they proposed ADAMS/LifeMOD software to establish a bicycle-human integrated multibody dynamic model can be mentioned as an example of research concerned with investigating the impact of bicycle suspensions on cyclist's leg muscle forces. Maier et al. [7] focus their research on the design and validation of a multi-body model of a front suspension bicycle and a passive rider for the investigation of braking dynamics.

Thus, it can be seen that cycling is a very complex area composed of many aspects. However, in our article, we will further focus on stress analysis and consequent optimization of the critical points of the full-suspension mountain bike, concretely the bike Nukeproof Pulse Pro, version 2018 [27].

\section{Analysis of the Investigated Bicycle Frame-Condition and Background}

The general full-suspension mountain bicycle (Figure 1) differs from the traditional hardtail mountain bike in that it is equipped with a front suspension fork and a rear suspension system (composed of damper for shock absorbing and spring for rebounding) as well. The suspension system increases the comfort together with the safety of the ride when riding on rough terrain. These systems differ in complexity (due to a higher number of elements depending on the used suspension system) and the resulting driving characteristics. A common sign of all full suspension bicycles is the independent suspension of not only the front but also the rear wheel via the front and rear fork (rear triangle) with respect to the front frame triangle (main frame). The rear triangle is attached to main frame by a suspension system with one degree of freedom consisting of pins, rocker arms, and a shock absorber. It is the structure of the rear triangle, its assembly and geometry, that affects the ride characteristics the most. The rear triangle moves vertically via dumping the inertia forces (rider's and bicycle weight) when driving in terrain unevenness and, further, this vertical motion is distributed to the shock absorber by a pivot and rocker system. The shock absorber is a flexible element in the kinematics of the rear fork designed to absorb any forces and vibrations, slow down the rear triangle motion, dampen the compression, 
and regulate the subsequent speed of return to its original position (bounce) and thus increase comfort.

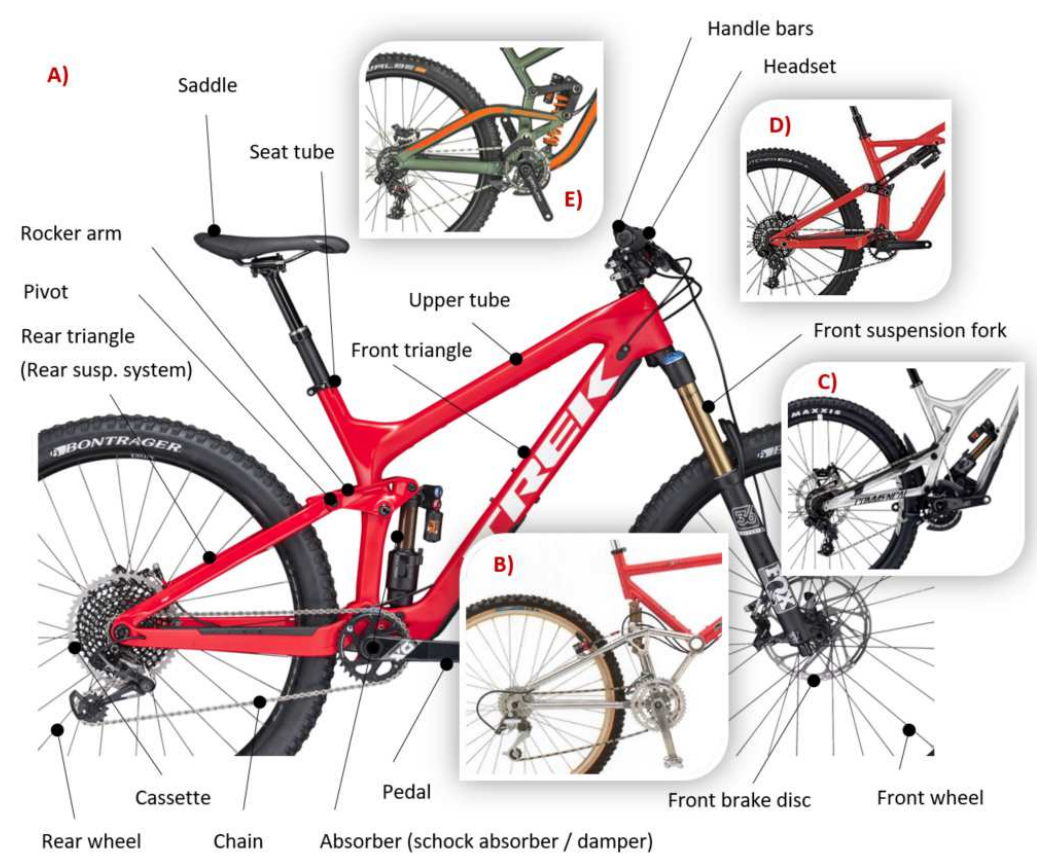

Figure 1. Basic features of general full suspension bike frame and different suspension systems comparison: (A)—Split Pivot on bicycle Trek Slash, (B)—Unified Rear Triangle (URT) system on Schwinn Homegrown, (C)—High Pivot on Commencal Supreme bike, (D)—Horst Link "FSR" on Specialized Enduro, (E)-Scott Gambler based on One pivot with levering/floating link system (based on [2]; illustration composed of individual images, sources: www.trek.com (accessed on 10 December 2019), www.scott.com (accessed on 5 May 2019), www.specialized.com (accessed on 8 June 2019), www.commencal.com (accessed on 10 October 2020).

Figure 1 shows the basic features of the general full suspension bike frame as well as introduces the different suspension systems designed by different bicycle manufacturers. Table 1 compares the advantages and disadvantages of the most used suspension systems (some of them shown in Figure 1), as well as the companies using these types of suspension systems.

The investigated frame of the Nukeproof Pulse Pro/version 2018 bicycle (Figure 2) consists of four main components shown in Figure 3 connected to each other by pins and bearings. The so-called "one pivot suspension with additional levering system" (see Table 1) is used where the fixed rear triangle rotates around the joint called the main bearing located in the front frame triangle over the crankset bottom bracket or crank spindle (Figure 2). The forces exerting the damper (shock absorber) with a total body length of $250 \mathrm{~mm}$ and a working stroke of $75 \mathrm{~mm}$ are transmitted from the rear wheel through to the rod and rocker arm. By using such suspension and geometry, the $210 \mathrm{~mm}$ rear wheel is able to travel. 
Table 1. Comparison of suspension systems [2].

\begin{tabular}{|c|c|c|c|}
\hline $\begin{array}{l}\text { Suspension } \\
\text { System }\end{array}$ & Advantages & Disadvantages & Company \\
\hline One pivot & $\begin{array}{l}\text { very simple, minimum } \\
\text { service requirements }\end{array}$ & $\begin{array}{l}\text { bad pedalling response } \\
\text { moving is affecting } \\
\text { by braking }\end{array}$ & $\begin{array}{l}\text { Dewilwork, } \\
\text { Morewood, Santa } \\
\text { Cruz, Canondale }\end{array}$ \\
\hline $\begin{array}{c}\text { One pivot } \\
\text { with levering }\end{array}$ & $\begin{array}{l}\text { better regulation of the } \\
\text { applied force on } \\
\text { the damper }\end{array}$ & $\begin{array}{l}\text { moving is affecting by } \\
\text { braking, moving of rear } \\
\text { tringle when pedalling }\end{array}$ & $\begin{array}{l}\text { Merida, Kona, Trek, } \\
\text { Transition, Scott }\end{array}$ \\
\hline $\begin{array}{l}\text { One-pivot } \\
\text { High Pivot }\end{array}$ & $\begin{array}{l}\text { eliminated impact of } \\
\text { braking to suspension }\end{array}$ & $\begin{array}{l}\text { long length of chain, } \\
\text { higher weight, used just } \\
\text { with downhill bikes }\end{array}$ & Commencal, Scott \\
\hline $\begin{array}{l}\text { Four-pivot } \\
\text { Horst Link }\end{array}$ & $\begin{array}{l}\text { simple system, almost no } \\
\text { pedalling squat }\end{array}$ & $\begin{array}{l}\text { suspension is sensitive to } \\
\text { small terrain unevenness, } \\
\text { affected by braking }\end{array}$ & $\begin{array}{l}\text { Canyon, Radon, } \\
\text { Specialized, Norco }\end{array}$ \\
\hline $\begin{array}{l}\text { Four-pivot } \\
\text { Split pivot }\end{array}$ & $\begin{array}{l}\text { the best drivability, a } \\
\text { small drop of the rear } \\
\text { triangle when pedalling, } \\
\text { removes brake squat }\end{array}$ & $\begin{array}{l}\text { higher weight, } \\
\text { patent litigation }\end{array}$ & $\begin{array}{l}\text { Pivot, Morewood, } \\
\text { Trek }\end{array}$ \\
\hline $\begin{array}{l}\text { Four-pivot } \\
\text { Twin link }\end{array}$ & $\begin{array}{l}\text { balanced movement, } \\
\text { suspension flexibility, } \\
\text { almost no suspension } \\
\text { moving when pedalling }\end{array}$ & $\begin{array}{l}\text { higher weight, higher } \\
\text { maintenance } \\
\text { requirements }\end{array}$ & $\begin{array}{l}\text { Santa Cruz, } \\
\text { Ibis, Giant }\end{array}$ \\
\hline
\end{tabular}

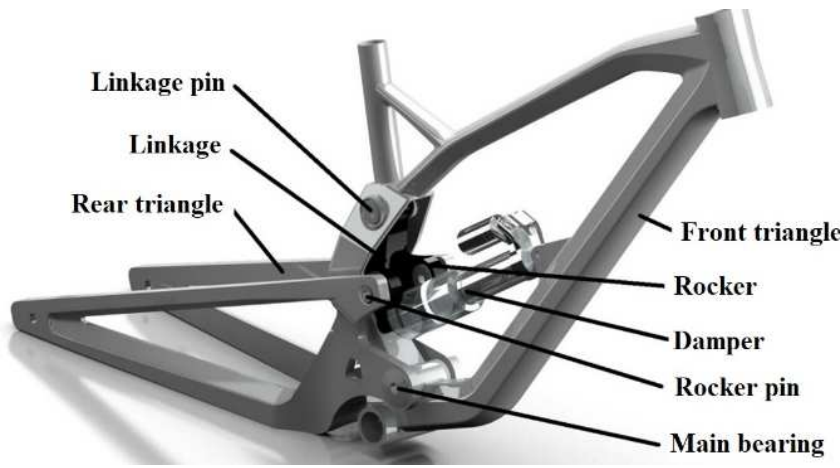

Figure 2. 3D model of investigated bicycle frame.

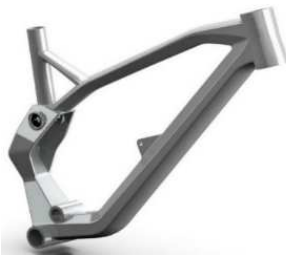

(a)

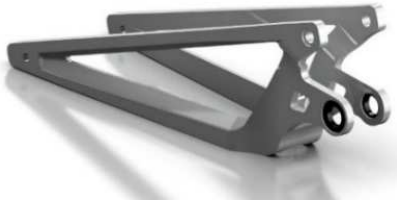

(b)

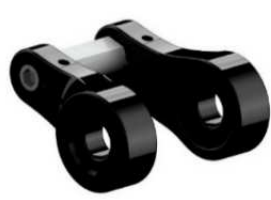

(c)

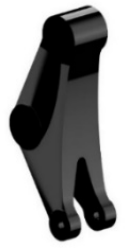

(d)

Figure 3. Original frame and suspension system components: front triangle (a), rear triangle with the main bearing (b), rod (c), and rocker arm (d). The dimensions are shown below (further figures).

\subsection{Investigated Frame Damage}

Figure $4 \mathrm{a}$ shows the specific location of the front triangular frame where the damage occurred during use and will therefore be studied. The damaged area is located near the "pocket" on the welded part (red box). The pocket is designed as a free space where the linkage and rocker arm move during the operation of the suspension system. In Figure $4 b-d$, there is shown a series of detailed photographs from different angles showing 
the exact location of the frame break (arrows). The material is cracked in both ribs and passes through the entire thickness of the material ( $4 \mathrm{~mm}$ at the investigated point). The created crack has a length of approximately $20 \mathrm{~mm}$.

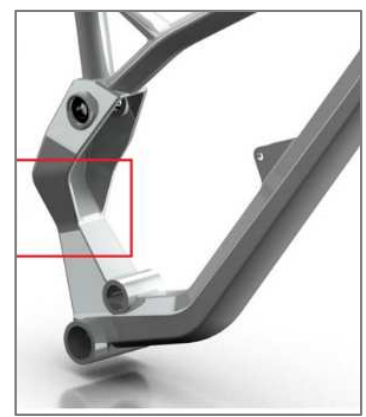

(a)

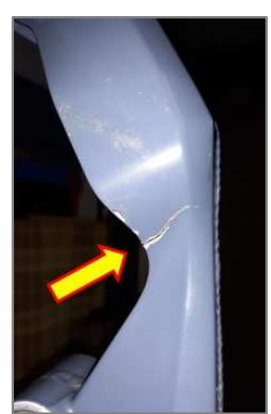

(b)

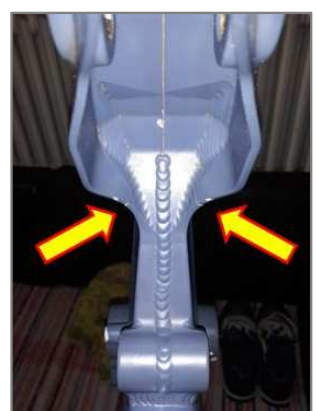

(c)

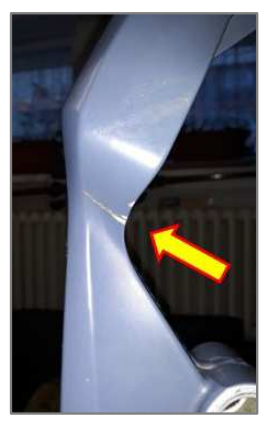

(d)

Figure 4. Researched location of damaged place on the front triangle (a) and a detailed view of the damage from different angles (b-d) [2].

\subsection{Frame Kinematics and Motion Analysis}

The kinematics of a full suspension bicycle frame are usually made up of a system of "tubes" and rocker bars connected by pins. The frame kinematics define how the wheel moves throughout the full stroke, determine the rear wheel response on terrain unevenness, and transform this motion into shock absorber compression. In order to understand motion kinematics as a set of properties for different design solutions, it is important to define some general terms (see Figure 5) [28]:

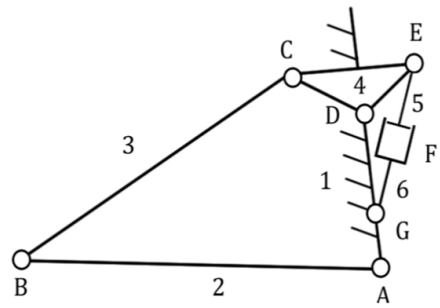

Figure 5. Simplified structure of rear triangle and suspension—general terms explanation. B, C, D

Pivot-rotary connection of two bodies by means of a pin and a bearing, e.g., nodes A,

Link-an imaginary rod-a part connecting two pivots. The bodies 2, 3 and 4.

Travel-the maximum vertical wheel motion, whether rear or front one, usually in millimetres or inches. Mountain bike categories differ in stroke size, typically ranging from $80 \mathrm{~mm}$ (XC models) up to $250 \mathrm{~mm}$ (downhill specials). Front fork travel ranges from 80 to $200 \mathrm{~mm}$.

Stroke (traveling)—value indicating maximum damper extension/compression in millimetres. For instance, the damper with " $215 \times 63$ ” has $63 \mathrm{~mm}$ of stroke and a total unloaded length of $215 \mathrm{~mm}$.

Static Sag-relative compression (typically 25-30\%) of the damper under a certain rider's weight.

MR (Motion Ratio) — the kinematic arrangement changes in time, causing the nonlinear characteristic of the damper compression, during the stroke of suspension and rear triangle.

LR (Leverage Ratio)-reciprocal parameter to the MR; evaluation of the suspension behavior.

Rear wheel axis trajectory-trajectory described by rear wheel axis during the stroke. In general, it is a 2D curve (usually circle section) depending on suspension and rear triangle 
design. It is the direction and shape of the trajectory that define how the suspension will behave at the beginning of the stroke and determine the sensitivity of the suspension to small terrain unevenness.

A degrees of freedom calculation-the rear structure of the bicycle is multibody mechanism composed of an imaginary set of rods connected by rotary joints (pins) to the basic body (front triangle) and a two-way sliding linkage (the damper). This system always has one degree of freedom (DOF).

$$
i=i_{v}(n-1)-\Sigma \xi \mathbf{i},
$$

$\begin{array}{lll}i_{v} & {[-]} & \text { number of DOF (for 2D case, } i_{v}=3 \text { ), } \\ n & {[-]} & \text { number of bodies, } \\ \Sigma \xi_{i} & {[-]} & \text { number of DOF taken by constraints. }\end{array}$

Calculation in the case of Figure 2 (each link takes 2 DOF):

$$
i=3 \cdot(6-1)-14=1^{\circ} \mathrm{DOF},
$$

Compression curve-defines the relation/dependence between the wheel stroke and the compression of the shock absorber regarding the frame and suspension design. However, it is more suitable to describe it via a gradient curve, steepness of the compression curve, or its derivation according to the rear wheel stroke.

$$
M_{R}=\frac{d Y_{s}}{d Y_{w}}[-]
$$

YS

$Y W$
$[-]$

$[-]$ shock compression, rear wheel stroke.

According to the given shape and course of the compression curve, the suspension as progressive, linear or degressive can be evaluated. Figure 6 shows the shock absorber compression curve (blue), as well as the gradient curve (red) for the investigated Nukeproof Pulse bike, plotted in software Linkage X3 (Racooz Software, Budapest, Hungary, https: / / www.bikechecker.com/ (accessed on 10 December 2019)). It is obvious that the compression curve for the Nukeproof Pulse can be considered as linear in the major range (up to approx. $150 \mathrm{~mm}$ of stroke), which means that the beginning of suspension is sensitive while the end is more progressive.

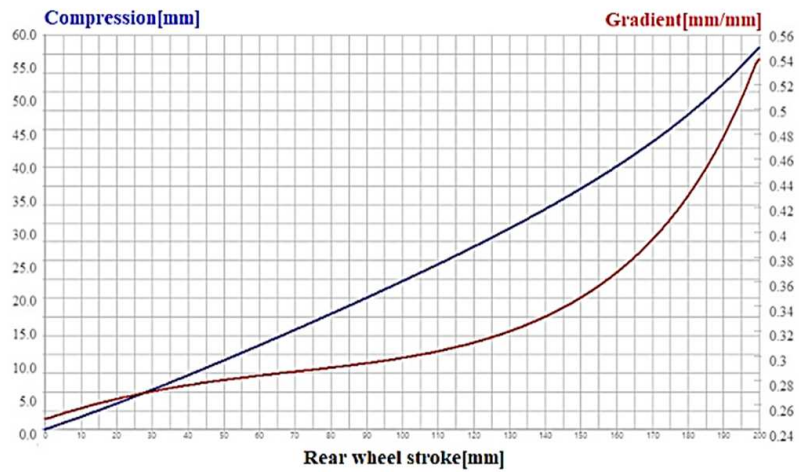

Figure 6. Shock absorber compression curve and MR dependence on researched frame [2].

In general, it is not possible to determine which curve type is optimal. However, for long and big jumps, the progressive compression curve can be considered as more suitable due to higher sensitivity at the beginning of the stroke followed by relatively higher stiffness as well as control and stability of the bike at the end. For downhill or cross-country 
style, a linear or degressive curve is more suitable when the force required to compress the damper increases linearly through the stroke.

Using the Linkage X3 software, we determined the boundary conditions of the movement of the components while driving (in planar/2D representation). Figure 7a shows an unloaded frame where the trajectories of the movement of the individual axes of the bicycle can be seen. Figure $7 \mathrm{~b}$ shows a frame at $200 \mathrm{~mm}$ full-stroke (the bicycle is bottomed out). By comparing both figures, it is obvious that, during the downward movement of the frame (impact suspension), the main dimensions of the frame change, e.g., shortening the distance of the wheel axes, the angle of the front fork, etc.

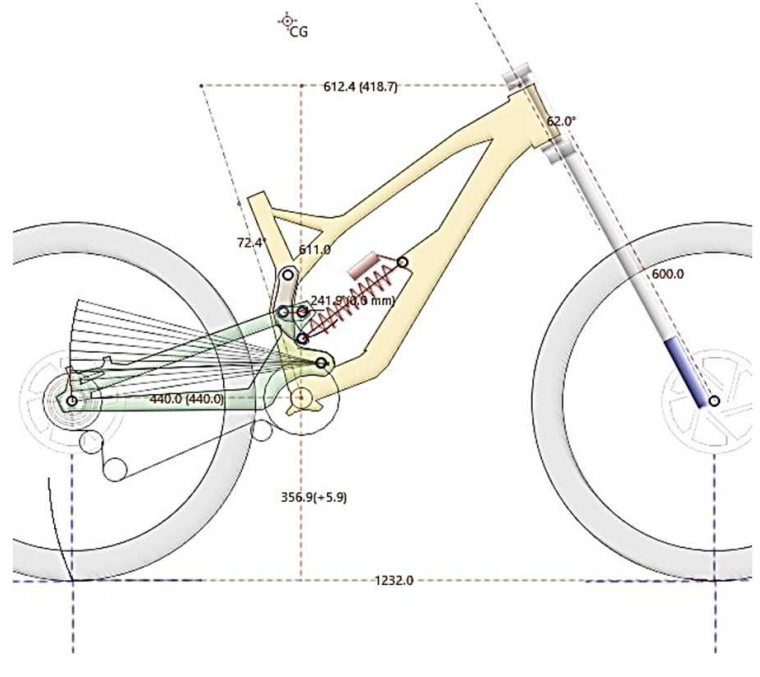

(a)

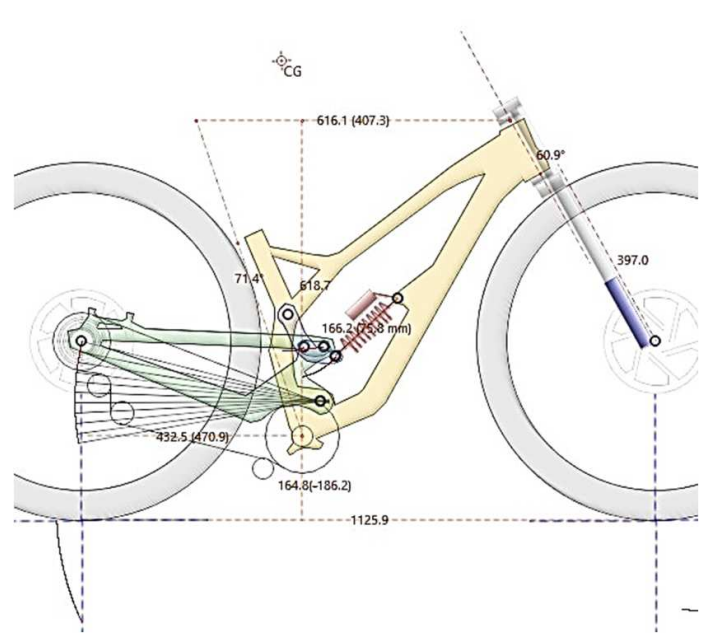

(b)

Figure 7. Frame geometry at unloaded position at $0 \mathrm{~mm}$ of stroke (a), and fully loaded position at $200 \mathrm{~mm}$ of stroke (b), (carried out in software Linkage X3) [2].

\subsection{Material Characteristics}

The investigated frame is made of aluminum alloy AL 6061-T6 belonging to the structural duralumin group, and it is widely used in the production of bicycles [29]. It offers a suitable combination of properties-lightweight on one hand, and sufficient strength, hardness, good machinability, suitability for forming and excellent weldability on the other. The improvement of the mechanical properties of this alloy can be achieved by suitable heat treatment (assigned as T6). A typical welding method is electric arc welding using Tungsten Inert Gas (TIG) or Metal Inert Gas (MIG) welding method, respectively. Any strength loss (up to 40\%, similarly to Al6061-T4) in the heat-affected zone near the welding joints can be eliminated by local reprocessing. It is used in the production of long constant cross-sectional shapes made by pressing it through a mold or hot forging.

Due to its excellent mechanical and technological properties, this alloy is mainly suitable for the production of automotive and vehicle parts [30], especially those that are exposed to high mechanical stress. The malleable cast iron AL 6061-T6 has a tensile strength of at least $290 \mathrm{MPa}$ and yield strength of at least $240 \mathrm{MPa}$ [30,31]. At a thickness of $6.35 \mathrm{~mm}$ or less, it has an elongation of $8 \%$ or more. With thicker parts, it has an elongation of $10 \%$ [32]. Selected mechanical properties and the chemical composition of the AL6061-T6 alloy can be seen in Table 2 . 
Table 2. Mechanical properties and chemical composition of the AL6061-T6 alloy [2,30].

\begin{tabular}{|c|c|c|c|c|}
\hline Type & Unit & Value & Element & $\%$ \\
\hline \multicolumn{3}{|c|}{ Mechanical Properties } & \multicolumn{2}{|c|}{ Chemical Composition } \\
\hline Hardness, Brinell & {$[-]$} & 95 & $\mathrm{Al}$ & $95.8-98.6$ \\
\hline Hardness, Knoop & {$[-]$} & 120 & $\mathrm{Cr}$ & $0.04-0.35$ \\
\hline Hardness, Rockwell A & {$[-]$} & 40 & $\mathrm{Cu}$ & $0.15-0.4$ \\
\hline Hardness, Rockwell B & {$[-]$} & 60 & $\mathrm{Fe}$ & Max 0.7 \\
\hline Hardness, Vickers & {$[-]$} & 107 & $\mathrm{Mg}$ & $0.8-1.2$ \\
\hline Strength limit & [MPa] & 310 & $\mathrm{Mn}$ & Max 0.15 \\
\hline Yield Strength & [MPa] & 276 & $\mathrm{Si}$ & $0.4-0.8$ \\
\hline Tensibility & {$[\%]$} & $12-17$ & $\mathrm{Ti}$ & Max 0.15 \\
\hline Elasticity module & [GPa] & 68.9 & $\mathrm{Zn}$ & Max 0.25 \\
\hline Notched tensile strength & [MPa] & 324 & other, elements & Max 0.05 \\
\hline $\begin{array}{l}\text { The greatest bearing } \\
\text { strength }\end{array}$ & [MPa] & 607 & other, overall & Max 0.15 \\
\hline Bearing strength & [MPa] & 386 & & \\
\hline Poisson's number & {$[-]$} & 0.33 & & \\
\hline Fatigue force & [MPa] & 96.5 & & \\
\hline Machinability & {$[\%]$} & 50 & & \\
\hline Shear module & [GPa] & 26 & & \\
\hline Shear strength & [MPa] & 207 & & \\
\hline
\end{tabular}

The investigated frame consists of profiled tubes and other components connected in one piece by TIG welding. Parts of the front frame triangle are made by forming (forging, bending, pressing) and machining (turning and milling).

\subsection{Riding Scenarios}

In the industry focused on the design and development of new bicycle frames, it is very difficult to analyze all possible scenarios and types of loading that may occur during pedalling, downhill, jumping, curve riding, etc. While designing a bicycle frame, the majority of manufactures use a dynamic coefficient to multiply the expected loads via dynamic or other types of coefficients (often determined on the basis of experience). Subsequently, the designers and engineers simulate the bicycle via an FEM analysis. If greater reliability is required, the prototype of the newly designed frame can be tested on a test stand where the specific conditions of the ride are simulated.

Based on the common empirical experience of each cyclist, it is possible to assume a quite strong dependence of the type of bicycle loading as well as loading of its individual structural components (frame, front fork, rear triangle, etc.) on the riding mode/regime/scenario. Therefore, it is necessary to analyze at least the most important scenarios, that can occur and can significantly influence the loading.

In our study, we consider these basic scenarios for the beginning:

(a) Downhill when riding out of the saddle with shifted rider's centre of gravity backwards (the stomach is approximately above the bicycle seat. Any elevation drops require a rearward shift of their centre of gravity to avoid the endo);

(b) Jumping without a shifted centre of gravity (Figure 8a);

(c) Jumping the drop by boosting the forward speed, initiating a hop with vertical momentum;

(d) Riding at a high speed through an inclined turn/banked turn/so-called berms (Figure 8b);

(e) Riding without saddle pedalling (Figure 8c).

A closer look at the individual cases mentioned above led us to the following conclusion: while the first four cases lead to similar symmetrical/quasi-symmetrical loading of the bicycle frame (the resultant force lies in the plane of the frame or this force is deflected by a small angle to the plane of symmetry and may be neglected), in the last case (out of saddle pedalling) there is a significant asymmetrical loading of the frame (twisting, bending outside the plane of the frame, etc.). Therefore, we further decided to consider representatives of both types of loads:

- $\quad$ Type I-symmetrical loading (cases a, b, c, d);

- $\quad$ Type II-asymmetrical loading (case e). 


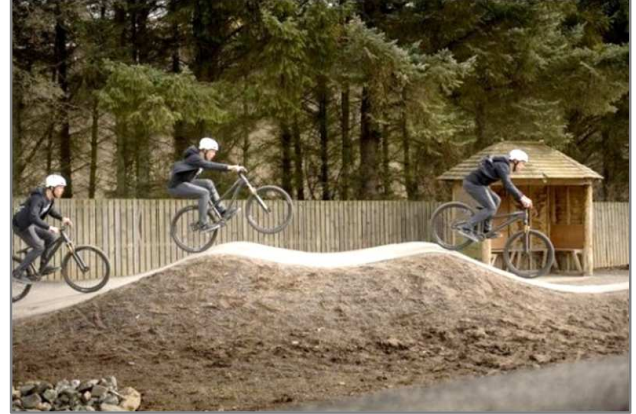

(a)

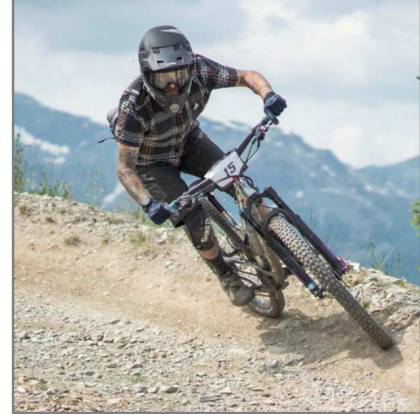

(b)

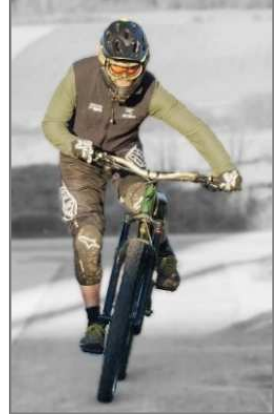

(c)

Figure 8. Different riding scenarios: (a) jumping without a shifted centre of gravity; (b) riding at high speed through an inclined turn/banked turn; (c) riding out of saddle pedalling.

\subsection{Loading of the Bicycle Frame while Driving}

When riding a bicycle, the frame is loaded by its own weight, the weight of the additional components, the rider's weight, the inertia effects while braking, the dynamic forces generated when driving over rough terrain, and the driving style itself. These loads act in various combinations, and the so-called driving scenario (previous chapter) has a significant impact too. It is difficult and time-consuming to analytically describe precisely the overall effect of the combined loading. Therefore, the calculation for static and dynamic loads is used. The braking load can be included in the dynamic analysis.

Static load of bicycle frame-is used in the preliminary design phase when we want to find out what forces are acting on the frame, individual components, and spring preloading. However, it can be reached only under specific conditions. The static load simulates driving at a constant speed, without braking and acceleration, on a perfect surface without bumps while the rider is at rest position and does not change the center of gravity position while driving.

Dynamic load of bicycle frame-determines how the bicycle frame is stressed under more realistic conditions. The dynamic load is constantly changing while driving and it is affected by several factors. The main factors influencing the level of dynamic load while driving we can consider are:

- The rider's position when driving;

- Braking resp. bicycle acceleration;

- Terrain nature-slope, unevenness, jumps, etc.;

- Rider's skills-technique and driving style.

It is almost impossible to quantify precisely the dynamic forces acting on the frame at a certain point due to these factors and the highly variable nature of the load. This is also the reason why dynamic effects are sometimes replaced by a coefficient that expresses the dynamic load as a function of static loading (it is the numerical coefficient that multiplies the calculated static load of the frame and components). When designing the bicycle frame, a dynamic coefficient of 3 is used to calculate the dynamic load.

\section{Simple Bicycle Load Acting in the Frame's Symmetry Plane}

When calculating the static load of the bicycle, it can be supposed that the main forces acting on the bicycle frame are caused by the rider's weight. Assuming the rider stands on the pedals, his weight ' $G$ ' is centered in the bottom bracket, as can be seen in Figure 9. This force is divided into contact points of both tires and the ground surface (reaction forces $F_{a}$ and $F_{c}$ ) and their ratio depending on the position of the rider's center of gravity (CG). Depending on its position, a certain percentage of the gravity force can be distributed through the handlebars. 


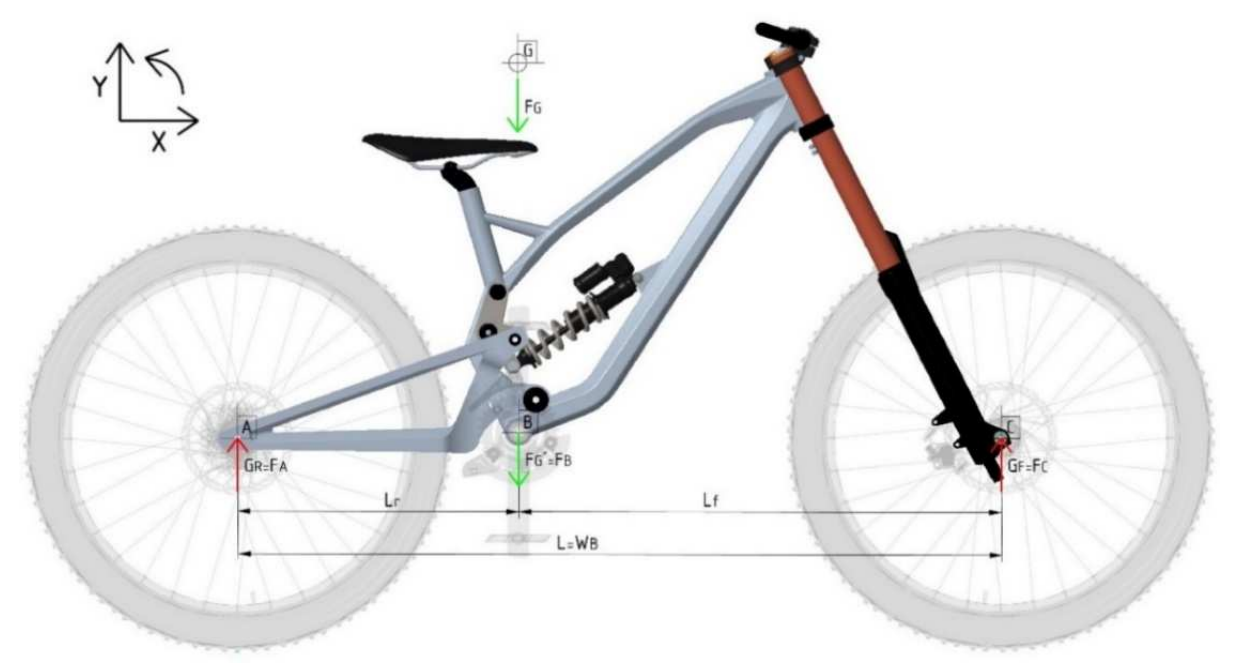

Figure 9. Basic external symmetrical load of bicycle frame.

Further, they are distributed to the frame via wheels, wheel shafts, front or rear fork. Unfortunately, this position is constantly changing during the ride with respect to the terrain profile, instant cyclist riding style, and the main working of the suspension system, etc. Given some empirical experiences, such a simplification can be accepted based on neglecting the effect of the CG shift towards the front wheel (we will consider this as the neutral position of the rider). The front wheel reaction force is distributed via the front fork into the head set, where the force $F_{c^{\prime}}$ can be placed. The rear wheel reaction force $F_{a}$ is transmitted to the shock absorber via the rear triangle and levering.

\begin{tabular}{|c|c|c|}
\hline $\mathrm{F}_{\mathrm{G}}$ & {$[\mathrm{N}]$} & gravity force caused by rider and bicycle weight, \\
\hline $\mathrm{F}_{\mathrm{G}^{\prime}}$ & {$[\mathrm{N}]$} & gravity force acting in bottom bracket, \\
\hline $\mathrm{G}_{\mathrm{F}}=\mathrm{F}_{\mathrm{C}}$ & {$[\mathrm{N}]$} & reaction to front wheel axis caused by gravity force, \\
\hline $\mathrm{G}_{\mathrm{R}}=\mathrm{F}_{\mathrm{A}}$ & {$[\mathrm{N}]$} & reaction to rear wheel axis caused by gravity force, \\
\hline $\mathrm{L}=\mathrm{W}_{\mathrm{B}}$ & [mm] & wheelbase, \\
\hline $\mathrm{L}_{\mathrm{f}}$ & [mm] & $\begin{array}{l}\text { distance of front wheel from center of gravity, } \mathrm{L}_{\mathrm{f}}=778 \mathrm{~mm} \text {; } \\
\text { according [27] }\end{array}$ \\
\hline $\mathrm{L}_{\mathrm{r}}$ & [mm] & $\begin{array}{l}\text { distance of rear wheel from center of gravity, } \mathrm{L}_{\mathrm{r}}=440 \mathrm{~mm} \text {; } \\
\text { according [27] }\end{array}$ \\
\hline $\begin{array}{l}\mathrm{F}_{\mathrm{C}^{\prime}} \\
\mathrm{G}^{\prime}\end{array}$ & $\begin{array}{l}{[\mathrm{N}]} \\
{[\mathrm{N}]}\end{array}$ & $\begin{array}{l}\text { force made in fork acting to head set, } \\
\text { gravity force. }\end{array}$ \\
\hline
\end{tabular}

The calculation is based on the equations of planar static equilibrium for forces and torques. The rider's weight and the weight of the bike with the components and geometry data (basic frame dimensions) will be used as input data. The external load was calculated first, then the analysis and calculations for the individual components of the frame and the suspension mechanism.

$$
\begin{gathered}
G^{\prime}=\left(m+m_{b}\right) \cdot g \\
\sum F_{i x}=0 \sum F_{i y}=0 \sum M_{i}=0
\end{gathered}
$$

$\begin{array}{lll}F_{i x} & {[\mathrm{~N}]} & \text { forces acting in } x \text {-axis, } \\ F_{i y} & {[\mathrm{~N}]} & \text { forces acting in } y \text {-axis, } \\ M_{i} & {[\mathrm{Nm}]} & \text { torque moment to a certain point, } \\ m & {[\mathrm{~kg}]} & \text { riders' weight, } \\ m_{b} & {[\mathrm{~kg}]} & \text { weight of bike with components, } \\ g & {\left[\mathrm{~m} \cdot \mathrm{s}^{-2}\right]} & \text { gravitational acceleration. }\end{array}$

For further calculation, the weight of the rider $m=90 \mathrm{~kg}$, the weight of the bicycle including components $m_{b}=15 \mathrm{~kg}$ and the gravitational acceleration constant $g=9.81 \mathrm{~m} \cdot \mathrm{s}^{-2}$ can be considered. Then, the gravitational force acting on the central shaft caused by both the rider's weight and the bicycle's weight with the components, after substituting into Equation (4), is rounded to $1030 \mathrm{~N}$. This force is further used in calculating the load of the 
other components. Force $F_{a}$ acts on the rear wheel shaft while the force $F_{c}$ acts on the front wheel shaft. After releasing the system and using the static equilibrium equations we have obtained the values of forces $F_{a}$ and $F_{c}$.

$$
\begin{gathered}
G^{\prime}=(90+15) \cdot 9.81=1030.05 \mathrm{~N} \\
\text { For next calculating }: G^{\prime}=1030 \mathrm{~N} \\
\sum F_{i x}=0 ; \\
\sum F_{i y}=0 ; F_{A}+F_{C}-G^{\prime}=0 \\
\sum M_{i A}=0 ;-G^{\prime} \cdot L_{r}+F_{C} \cdot\left(L_{f}+L_{r}\right)=0 \\
L_{r}=440 \mathrm{~mm} ; L_{f}=778 \mathrm{~mm} ; F_{C}=\frac{G^{\prime} \cdot 440}{(440+778)}=372 \mathrm{~N} \\
F_{A}=G^{\prime}-F_{C}=658 \mathrm{~N}
\end{gathered}
$$

\subsection{Loadings on Individual Parts of the Bicycle Frame}

The external load and forces acting on individual frame components were calculated. Individual components are rigid bodies and can be considered as imaginary rod systems where reactions act in their joints. The resulting reactions have sliding and rotating effects.

Rear triangle-For the rear triangle shown in Figure 10, equilibrium equations can be constructed with respect to point 1 (main bearing axis) while the reaction forces induced the rear wheel force $F_{a}$. The reaction forces are restrained by the main bearing shaft and can be decomposed into $x$ and $y$ components $F_{1 x}$ and $F_{1 y}$.

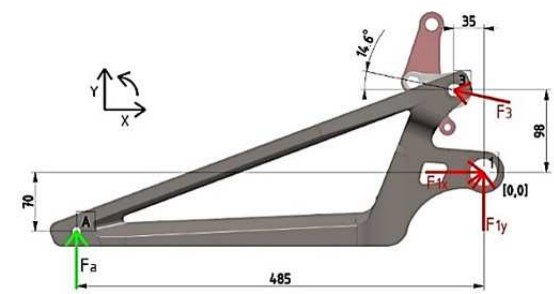

Figure 10. Static release for rear triangle calculation [2].

Then, the force $\mathrm{F}_{3}$ located in contact point 3 can be calculated, which represents the joint connecting the rear triangle and rocker body. Similarly, force $F_{3}$ can be decomposed into $x$ and $y$ components $F_{3 x}$ and $F_{3 y}$.

$$
\begin{gathered}
\sum F_{i x}=0 ; \quad F_{1 x}-F_{3 x}=0 \\
\sum F_{i y}=0 ; \quad F_{A}+F_{1 y}+F_{3 y}=0 \\
\sum M_{i 1}=0 ; \quad-F_{A} \cdot 485+F_{3 x} \cdot 98-F_{3 y} \cdot 35=0 \\
F_{3 x}=F_{3} \cdot \cos \left(14.6^{\circ}\right) \\
F_{3 y}=F_{3} \cdot \sin \left(14.6^{\circ}\right) \\
F_{3}=F_{A} \frac{485}{\left(35 \cdot \sin \left(14.5^{\circ}\right)+98 \cdot \cos \left(14.6^{\circ}\right)\right)}=3710 \mathrm{~N} \\
F_{3 x}=F_{3} \cdot \cos \left(20.5^{\circ}\right)=3590 \mathrm{~N} \\
F_{3 y}=F_{3} \cdot \sin \left(20.5^{\circ}\right)=935 \mathrm{~N} \\
F_{1 x}=F_{3 x}=3590 \mathrm{~N}
\end{gathered}
$$




$$
F_{1 y}=-F_{3 y}-F_{A}=-1593 \mathrm{~N}
$$

Rod-When calculating the forces in Figure 11a, we considered that the rod is used as a pull member for the force transmission $\mathrm{F}_{3}$ from point 3 to point 4 in the rod. As input, we use force $\mathrm{F}_{3^{\prime}}$, the reacting force to $\mathrm{F}_{3}$, which was calculated above (Equation (17)). The calculated force $\mathrm{F}_{4^{\prime}}$ is the reaction axial force to the force $\mathrm{F}_{3^{\prime}}$.

$$
\begin{gathered}
F_{3}=-3710 \mathrm{~N} \\
\sum F=0 ; \quad F_{3 \prime}-F_{4}=0 \\
F_{4 \prime}=-F_{3 \prime}=3710 \mathrm{~N}
\end{gathered}
$$

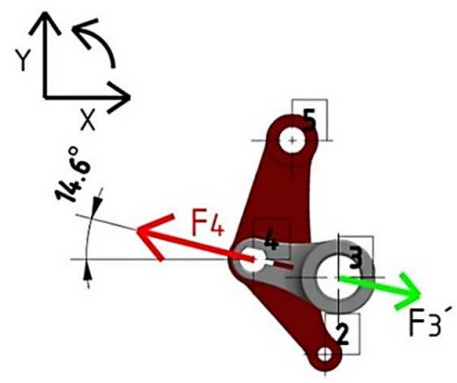

(a)

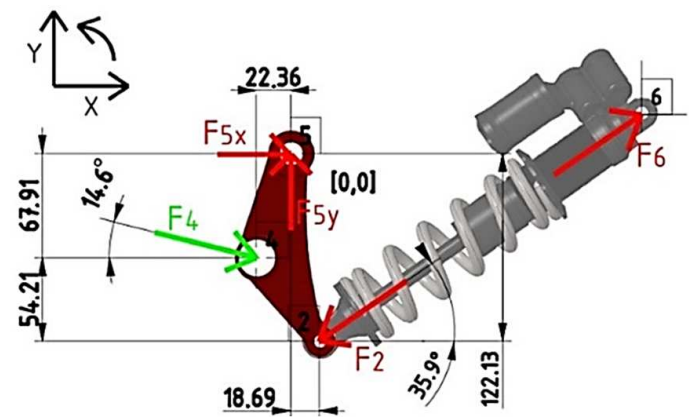

(b)

Figure 11. Balance of forces on the rod (a) and rocker arm (b) [2].

Rocker arm-When calculating the forces acting in the rocker arm Figure 11b, we can consider the input force $\mathrm{F}_{4}$ acting in point 4 is the reaction compressive force to force $\mathrm{F}_{4^{\prime}}$, which was calculated above (Equation (22)). The calculated forces acting at points 2 and 5 are shown as well. Forces $F_{5 x}$ and $F_{5 y}$ are made by the rotation of the rocker arm around point 5 . The force $F_{2}$ acting in point 2 is the reaction axial force made when the force $F_{4}$ is transmitted to the damper. The calculation proceeds as in the previous chapters.

$$
\begin{gathered}
F_{4}=3710 \mathrm{~N} \\
\sum F_{i x}=0 ; \quad F_{4 x}-F_{2 x}+F_{5 x}=0 \\
\sum F_{i y}=0 ; \quad F_{5 y}-F_{4 y}-F_{2 y}=0 \\
\sum M_{i 2}=0 ; \quad F_{4 x} \cdot 67.91-F_{4 y} \cdot 22.36-F_{2 y} \cdot 18.69-F_{2 x} \cdot 122.13=0 \\
F_{2 x}=F_{2} \cdot \cos \left(35.9^{\circ}\right) \\
F_{2 y}=F_{2} \cdot \sin \left(35.9^{\circ}\right) \\
F_{4 x}=F_{4} \cdot \cos \left(14.6^{\circ}\right)=3590 \mathrm{~N} \\
F_{4 y}=F_{4} \cdot \sin \left(14.6^{\circ}\right)=935 \mathrm{~N} \\
F_{2}=F_{4} \frac{\left(67.91 \cdot \cos \left(14.6^{\circ}\right)-22.36 \cdot \sin \left(14.6^{\circ}\right)\right)}{\left(18.69 \cdot \sin \left(35.9^{\circ}\right)-122.13 \cdot \cos \left(35.9^{\circ}\right)\right)}=2534 \mathrm{~N} \\
F_{2 x}=F_{2} \cdot \cos \left(52.9^{\circ}\right)=2053 \mathrm{~N} \\
F_{2 y}=F_{2} \cdot \sin \left(52.9^{\circ}\right)=1486 \mathrm{~N} \\
F_{5 x}=F_{2 x}-F_{4 x}=-1537 \mathrm{~N} \\
F_{5 y}=F_{2 y}+F_{4 y}=2421 \mathrm{~N}
\end{gathered}
$$




\subsection{Forces Acting on the Bicycle Frame}

Table 3 shows the sizes of the force components made by static loads acting. Table 3 shows individual forces within the frame and suspension system corresponding to different riders' weights $\mathrm{m}$. The weight of the frame with components is considered to be the same for all cases $(15 \mathrm{~kg})$.

Table 3. Resulting forces acting in the bicycle frame according to the weight of the rider [2].

\begin{tabular}{|c|c|c|c|c|c|c|c|}
\hline \multirow{2}{*}{$\begin{array}{l}\text { Individual } \\
\text { Force }[N]\end{array}$} & \multicolumn{7}{|c|}{ Riders Weight m [kg] } \\
\hline & 70 & 75 & 80 & 85 & 90 & 95 & 100 \\
\hline $\mathrm{F}_{\mathrm{b}}[\mathrm{N}]$ & -834 & -883 & -932 & -981 & -1030 & -1079 & -1128 \\
\hline $\mathrm{F}_{\mathrm{a}}[\mathrm{N}]$ & 533 & 564 & 595 & 627 & 658 & 689 & 721 \\
\hline $\mathrm{F}_{\mathrm{C}}[\mathrm{N}]$ & 301 & 319 & 337 & 354 & 372 & 390 & 408 \\
\hline $\mathrm{F}_{1 \mathrm{x}}[\mathrm{N}]$ & 2906 & 3077 & 3248 & 3419 & 3590 & 3761 & 3932 \\
\hline $\mathrm{F}_{1 \mathrm{y}}[\mathrm{N}]$ & -1290 & -1366 & -1441 & -1517 & -1593 & -1669 & -1745 \\
\hline $\mathrm{F}_{2}[\mathrm{~N}]$ & 2051 & 2172 & 2293 & 2413 & 2534 & 2655 & 2775 \\
\hline $\mathrm{F}_{2 \mathrm{x}}[\mathrm{N}]$ & 1662 & 1759 & 1857 & 1955 & 2053 & 2150 & 2248 \\
\hline $\mathrm{F}_{2 \mathrm{y}}[\mathrm{N}]$ & 1203 & 1274 & 1344 & 1415 & 1486 & 1557 & 1627 \\
\hline $\mathrm{F}_{3}[\mathrm{~N}]$ & 3003 & 3180 & 3356 & 3533 & 3710 & 3886 & 4063 \\
\hline $\mathrm{F}_{3 \mathrm{x}}[\mathrm{N}]$ & 2906 & 3077 & 3248 & 3419 & 3590 & 3761 & 3932 \\
\hline $\mathrm{F}_{3 \mathrm{y}}[\mathrm{N}]$ & 757 & 802 & 846 & 891 & 935 & 980 & 1024 \\
\hline $\mathrm{F}_{4}[\mathrm{~N}]$ & 3003 & 3180 & 3356 & 3533 & 3710 & 3886 & 4063 \\
\hline $\mathrm{F}_{4 \mathrm{x}}[\mathrm{N}]$ & 2906 & 3077 & 3248 & 3419 & 3590 & 3761 & 3932 \\
\hline $\mathrm{F}_{4 \mathrm{y}}[\mathrm{N}]$ & 757 & 802 & 846 & 891 & 935 & 980 & 1024 \\
\hline $\mathrm{F}_{5 \mathrm{x}}[\mathrm{N}]$ & -1244 & -1318 & -1391 & -1464 & -1537 & -1611 & -1684 \\
\hline $\mathrm{F}_{5 \mathrm{y}}[\mathrm{N}]$ & 1960 & 2075 & 2191 & 2306 & 2421 & 2536 & 2652 \\
\hline $\mathrm{F}_{6}[\mathrm{~N}]$ & -2051 & -2172 & -2293 & -2413 & -2534 & -2655 & -2775 \\
\hline
\end{tabular}

\subsection{Preliminary Structural Analysis of Assembled Frame}

The software Creo Parametric 2.0 (PTC, Boston, MA, USA, https:/ / www.ptc.com/en/ products / creo (accessed on 20 October 2019)) was applied to create the CAD model of the bicycle frame. Subsequently, the CAD model was exported to ANSYS/Workbench 19.2 (ANSYS, Inc., Canonsburg, PA, USA, https:/ / www.ansys.com/ (accessed on 20 October 2019)) via the Standard for the Exchange of Product Data (STEP) exchange format, where we used previously calculated forces to load the model and then we determined the critical places on the frame.

Dynamic forces must be taken into account in order to correctly identify critical points of the bicycle frame. The force $F_{b}$ (weight of the rider and bicycle together) multiplied by a dynamic coefficient equal to 3 was used for further preliminary structural analysis. The dynamic force $\mathrm{F}_{\mathrm{bd}}=3150 \mathrm{~N}$ acts in the bottom bracket. The damper was replaced by a rigid member for simplification. The simulation results show (Figure 12) that the maximum stress value $\sigma_{\max }=73 \mathrm{MPa}$ is within the permitted range and is located in the weld joint of the head set and the bottom frame tube.

\subsection{Structural Analysis of Front Frame Triangle}

Only the main triangular frame was loaded when determining the critical points of the investigated frame. As input parameters for the calculation, we chose all forces acting in the component, multiplied by a dynamic coefficient of size 3 . The sizes of the forces used in the calculation are shown in Table 4, and the locations and directions of the resulting forces are shown in Figure 13. 


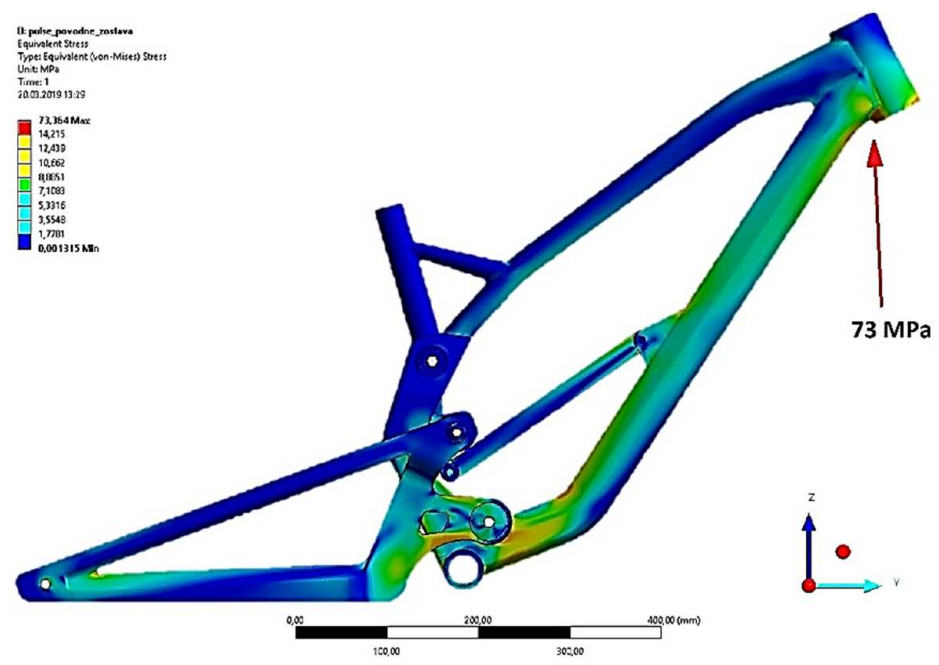

Figure 12. Preliminary static structural analysis of assembled main frame (without front fork) [2].

Table 4. Sizes of forces used in the structural analysis calculation [2].

\begin{tabular}{ccc}
\hline Force & Static Force $[N]$ & Dynamic Force [N] \\
\hline$F_{b}[N]$ & 1030 & 3090 \\
$F_{c}[N]$ & 372 & 1116 \\
$F_{1 x}[N]$ & 3590 & 10,770 \\
$F_{1 y}[N]$ & 1593 & 4779 \\
$F_{5 x}[N]$ & 1537 & 4611 \\
$F_{5 y}[N]$ & 2421 & 7263 \\
$F_{6 x}[N]$ & 2053 & 6159 \\
$\mathrm{~F}_{6 y}[N]$ & 1486 & 4458 \\
\hline
\end{tabular}

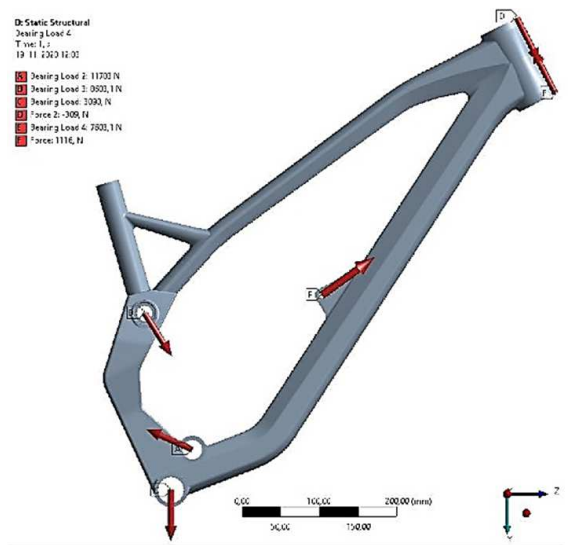

(a)

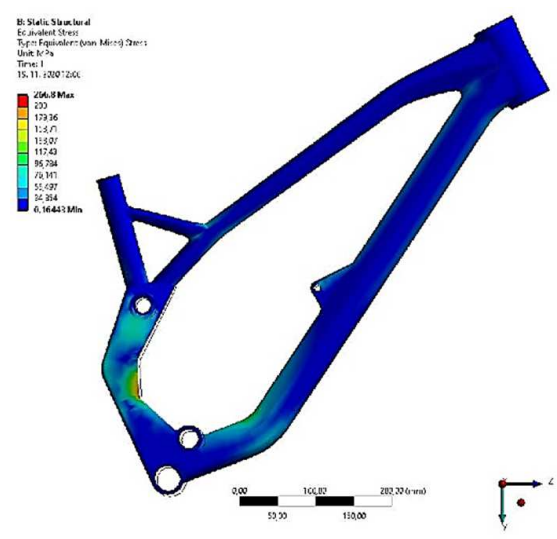

(b)

Figure 13. Locations and directions of forces used for calculation (a) and stress analysis of front triangle side view (b) [2].

We have compared our model with the data published in a study by Redfield [15] to confirm or correct our assumptions about the forces acting on the bicycle frame during adverse conditions. Within his study, a bond graph model of a mountain bike and rider was created to develop baseline predictions for the performance of mountain bikes during large excursion manoeuvers such as drops, jumps, crashes, and rough terrain riding. The model assumes planar dynamics, a hard-tail (front suspension only) bicycle and a rider fixed to the bicycle.

He analysed several cases/scenarios while riding a bicycle in rough terrain. Among other things, he mentioned two cases that are the most important for us as well. At the 
beginning, it is the case of riding downhill when out of the saddle with the rider's centre of gravity shifted backwards (the stomach is approximately above the bicycle seat and any elevation drops require a rearward shift of their centre of gravity to avoid the endo). The second one was the case of jumping without a shifted centre of gravity. Unfortunately, both cases have some limitations for us. His model does not contain a rear suspension system (hardtail bike) and simulates only partially "suspension via legs" (kind of "semi-rigid connection" between rider and bicycle). Despite these limitations, the conclusions of this study can be extrapolated to our set of analyses.

He concludes that for the first case (shifted centre of gravity backwards, riding downhill a ramp about $1 \mathrm{~m}$ high and half braking) forces (call them suspension forces) in a range up to approx. $2500 \mathrm{~N}$ can act on the bicycle frame and suspension system.

In the second case, he analyzed the scenario of jumping not by shifting the center of mass and/or braking, but by boosting the forward speed to approx. $16 \mathrm{~km}$ per hour and initiating a hop with vertical momentum before the drop. He concluded that this manoeuvre might result in much higher suspension forces (basically acting on the rear fork) although some other forces (e.g., braking) can have lower effects and thus can be neglected. In published graphs, there can be seen the peak force which occurs at the impact. The peak force can exceed over $6000 \mathrm{~N}$, which the suspension has to tolerate during jumps like this. He noticed that these forces are double those of the nominal case, and triple those of the previous case. A reliable bicycle frame must be designed to withstand these large, impulsive loads.

Based on this, we can conclude that our prediction corresponds quite accurately with the data from the study [15]. However, we would like to point out that in our case, the situation may be even more favorable. Certain additional reductions of the acting forces can be assumed due to the fully suspended bicycle frame, where a considerable amount of the forces (occurred during the first contact phase between the wheels and the ground-impact) should be absorbed by the suspension system.

The simulation results show stress concentration (Figure 14, red and orange color) in the area where the damage occurred, probably due to bending. In Figure $14 \mathrm{~b}$ there is shown a detailed view of the critical point of the frame where the stress concentration is obvious.

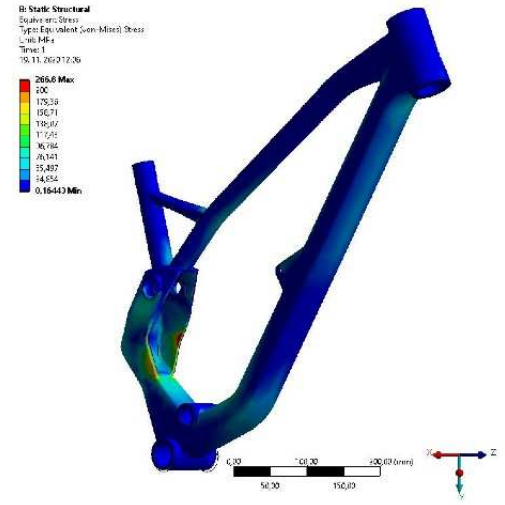

(a)
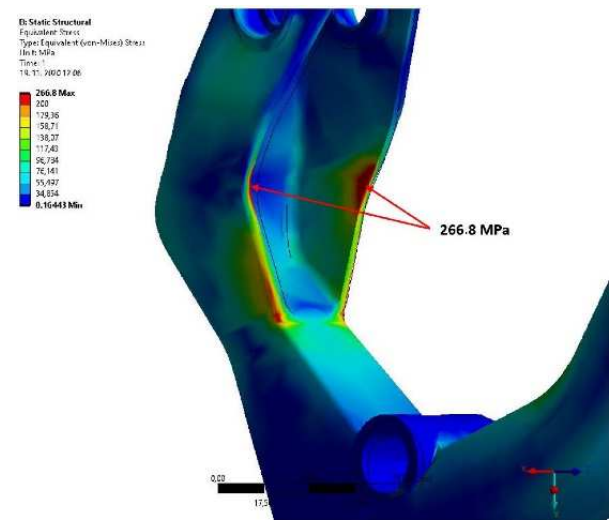

(b)

Figure 14. Stress analysis of front triangle isometric view (a) and detailed view (b) [2].

The simulation shows that there is significant stress increasing (several times higher than in all other places) in the damaged area when the bicycle is loaded. Thus, the area can be identified as a critical point. The maximum calculated stress is $266.8 \mathrm{MPa}$ while the yield strength of $\mathrm{Al} 6061-\mathrm{T} 6$ is $\mathrm{R}_{\mathrm{e}}=276 \mathrm{MPa}$. The resulting stress value is less than the yield strength of the material; however, due to the way of use (downhill bike), it is possible to expect that deformations/fractures will occur at the given place when the frame structure will be overloaded. 
Furthermore, the study focuses on finding sufficient improved design with higher frame stiffness in critical points and lower production cost at the same time.

\section{Improved Design Concept}

In the following chapter, several possible solutions will be proposed. One of them will be chosen for deeper study to determine the possibility of its production. There are several options available or design concepts for solving a critical damaged place on the investigated frame (Figure 15).

- New pocket design with higher wall thickness (Figure 15b)—it is based on replacing the critical part with a component with identical shape and external dimensions, but different wall thickness and production technology to reduce the resulting stresses. However, this solution is less suitable from the point of view of technology, total cost of production, and total weight;

- Pocket replacing by square profile with pin housing (Figure 15c) - the node design/shape will be changed while the suspension kinematics will not be affected regarding the position of the casing, and pin holes for the rocker arm pin remain without changes. The most significant change of this variant is that the suspension components (rocker arm and whole linkage) will be located outside the frame and not inside the pocket housing. Using a profile instead of an open pocket will result in reduced stress at the critical point.

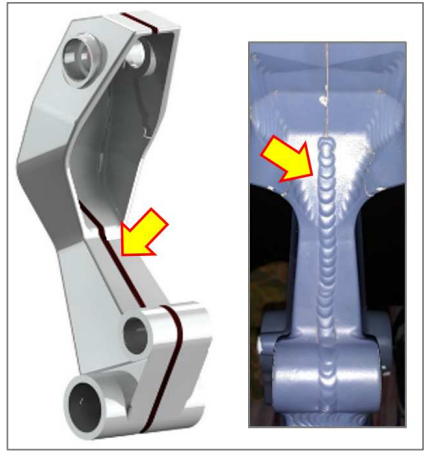

(a)

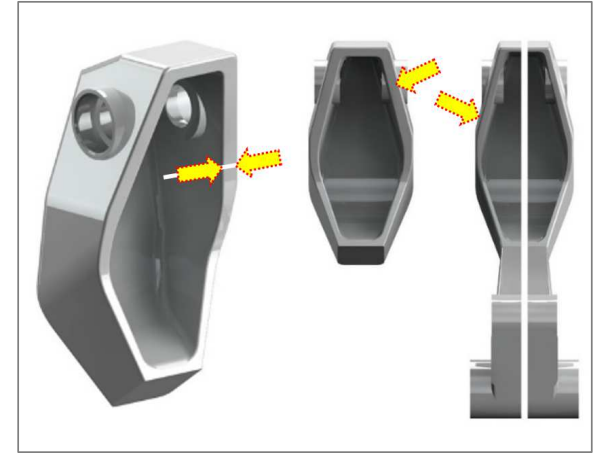

(b)

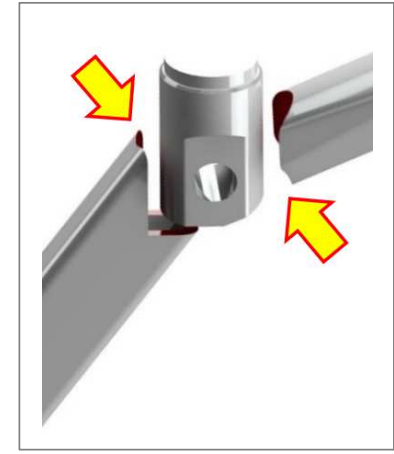

(c)

Figure 15. Original design (a) versus first (b) and second (c) conceptual design-new pocket design with higher wall thickness or replacement by welding assembly of square profile with pin housing (arrows show the welding connection or the wall thickness, respectively).

In Table 5, individual design solutions are compared regarding the used manufacturing technology. The table shows what additional components need to be manufactured for further use, the expected financial and technological demands, and the weight of the manufactured piece. For a small production series, which is our case, the forging technology is not suitable.

After comparing the financial and technological demands, as well as reviewing the available production technologies, the last option was chosen as a suitable solutionreplacing the critical point with a square profile with pin housing, manufacturing a bushing for the rocker arm pin, and subsequently welding it into the original frame. Figure 16 shows the new design of the front triangle. 
Table 5. Comparison of individual solutions.

$\left.\begin{array}{c}\text { Conceptual } \\ \text { Design }\end{array}\right) \begin{array}{r}\text { Forged } \\ \text { Rein } \\ \text { Wall }\end{array}$

(a)

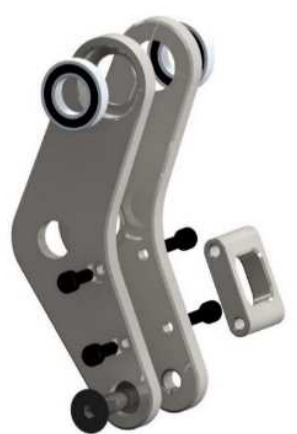

(b)

\section{Machined Pocket with Reinforced Wall-Thicker}

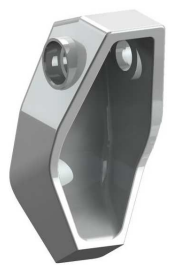

Upocket

Upper frame tube

pper frame tube

Linkage

Rocker Arm Pivots Pivots

Machining

Welding

$0.630 \mathrm{~kg}$
$0.630 \mathrm{~kg}$
Square Profile with Pin Housing

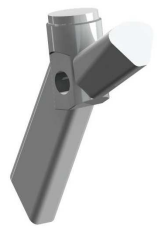

Bushing

Square profile Upper frame tube

Linkage

Rocker Arm Pivots Machining Turning Welding

$€ € \quad €$

3

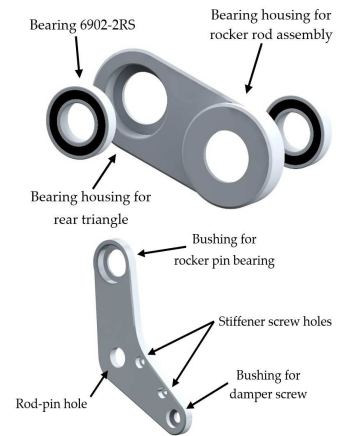

(c)

Figure 16. Improved frame design (a), assembly of linkage (b), assembly of rod rocker body (c).

Figure 16b shows the details of the selected design, where the resulting component consisting of three parts made of EN AW-6082 aluminum can be seen [33]. The first of them is the pin housing, which will be machined and welded to the saddle tube. The casing is made from a cylindrical workpiece of $40 \mathrm{~mm}$ in diameter. Furthermore, the pin hole is machined on a Computer Numerical Control (CNC) milling machine where the functional surfaces are aligned with hole for the rocker arm pin. Consequently, a shaped profile of the upper frame tube will be welded to the housing. The last part, made of the square profile (dimensions $40 \times 20 \times 4 \mathrm{~mm}$ ) and machined on a CNC milling machine, will replace the original pocket. The pin hole is located on the saddle tube axis, and the distance between the pin axis and the top of the seat tube is set to $175 \mathrm{~mm}$. Inserting the housing body into the saddle tube ensures required geometrical constraints, e.g., perpendicularity and coaxiality of the hole for the rocker arm pin. The new component is connected to the original frame using TIG welding technology.

Together with the improved frame design, it was necessary to produce a new rocker arm as well, due to changes in the location of the suspension members from inside the 
pocket (original design) to the outside (new improved design). It was also necessary to create new rods regarding the above changes in the solution of the suspension system. It is possible to keep the original, single-row ball bearings 6902-2RS with dimensions $15 \times 28 \times 7 \mathrm{~mm}$ for revolute joint. Figure $16 \mathrm{c}$ shows the rocker arm assembly composed of two rocker arm bodies, stiffeners between the rocker arm, four cylindrical head screws DIN 912 M5 × 20 mm, two ball bearings, and shock absorber screws. The rod assembly consists of a designed body with two bushings at both ends fitted for 6902-2RS bearings. The first one is for the rocker arm bearing while the second one with a $4 \mathrm{~mm}$ offset (due to existing welds on the rear triangle) is designed for the rear triangle bearing. The rocker assembly consists of three main components: two rocker arm bodies and a stiffener located between the rocker arms. The stiffener ensures that the entire rocker arm assembly does not twist when rear triangle is moving. There are two bearings 61902-2RS with dimensions $15 \times 28 \times 7 \mathrm{~mm}$.

For the production of frame components, the material EN AW-6082 was chosen, which has good weldability, similar mechanical properties to EN AW-6061, and is relatively available compared to the original material. Low-alloy stainless steel manganese-chrome suitable for cementation 16MnCr5 according to DIN 17,210 (14,220 according to STN) will be used for rod bodies as well as rocker arm manufacturing [34].

\section{New Frame Design under Symmetrical and Asymmetrical Loading}

The improved front triangle frame model was created in Creo Parametric 2.0. Stress analysis was performed in ANSYS/Workbench using the same procedure as in the first part of the case study when researching the original frame. The locations and directions of the forces are shown in Figure 17.
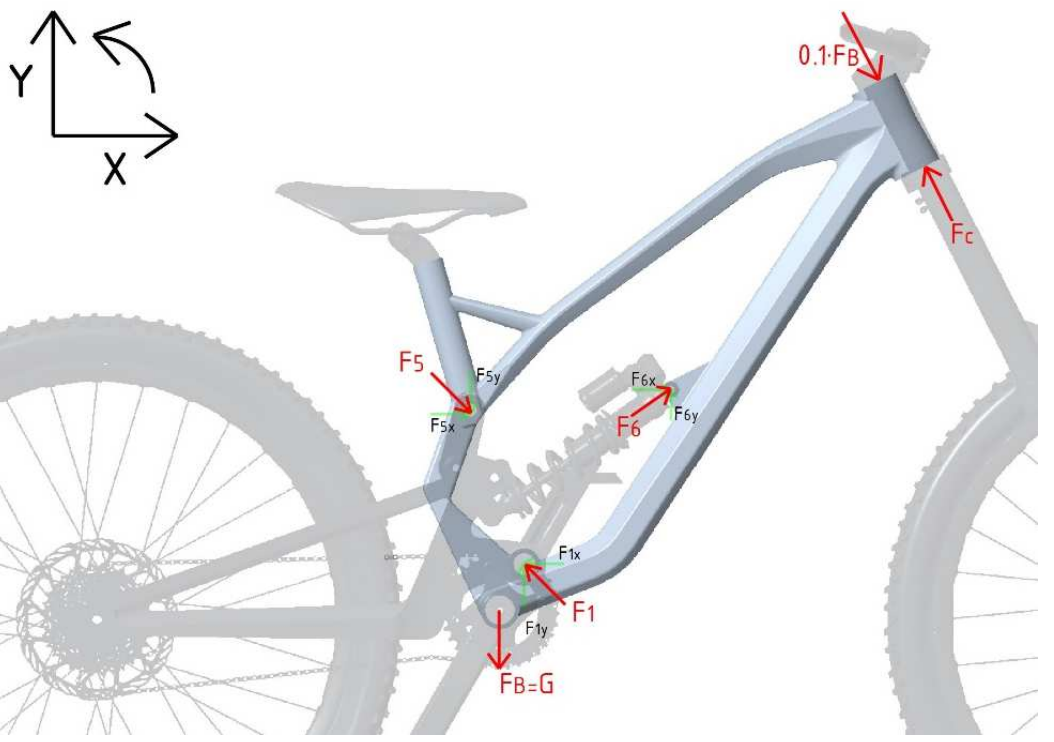

Figure 17. Locations and directions of forces used in calculation.

\subsection{Static Structural Analysis of Selected Solution}

The static structural analysis calculation is performed by using dynamic forces. The static force magnitude multiplied by a dynamic coefficient of magnitude 3 is shown in Table 6.

After static structural analysis calculation simulation in ANSYS/Workbench, we generated a graphical output picture of the generated stresses in the frame, which shows the higher stress in the area of damage. Figure 18 shows the graphical output of calculated stress. 
Table 6. Sizes of forces used in structural analysis calculation.

\begin{tabular}{ccc}
\hline Force & Static Force $[N]$ & Dynamic Force [N] \\
\hline$F_{b}[N]$ & 1030 & 3090 \\
$F_{c}[N]$ & 372 & 1116 \\
$F_{1 x}[N]$ & 3590 & 10770 \\
$F_{1 y}[N]$ & 1593 & 4779 \\
$F_{5 x}[N]$ & 1537 & 4611 \\
$F_{5 y}[N]$ & 2421 & 7263 \\
$F_{6 x}[N]$ & 2053 & 6159 \\
$F_{6 y}[N]$ & 1486 & 4458 \\
\hline
\end{tabular}

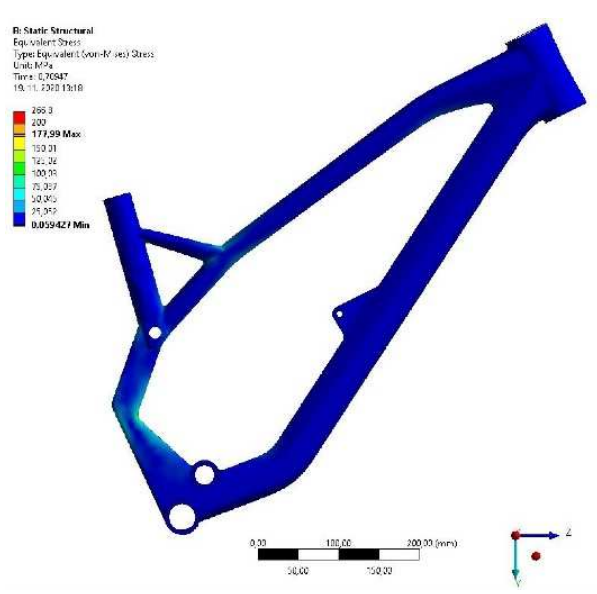

(a)

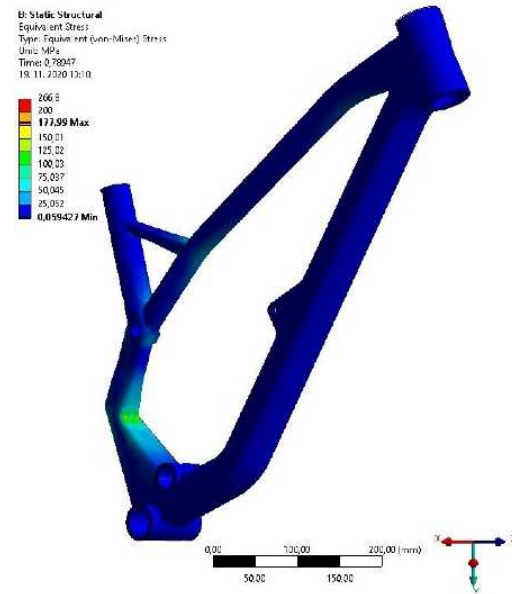

(b)

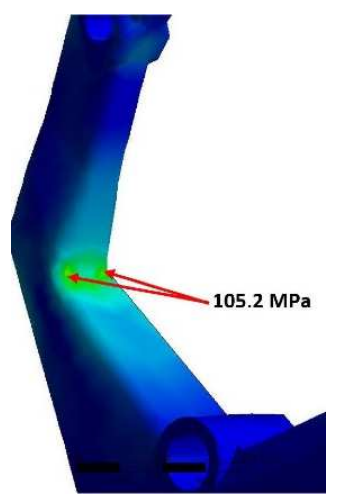

(c)

Figure 18. Stresses acting in front triangle, isometric view (a), side view (b) and detailed view (c).

In the chosen conceptual design, a multiple tension reduction in the resulting stresses can be observed, compared to the original design. When we compare the detailed simulation of both outputs from Figure 19, there is visibly reduced tension in the searched location from the original $\sigma_{\max }=266.8 \mathrm{MPa}$ to the current $\sigma_{\max }=105.2 \mathrm{MPa}$. There the maximum stress is almost 2.5 times lower (significant decreasing) than the original pocket design.
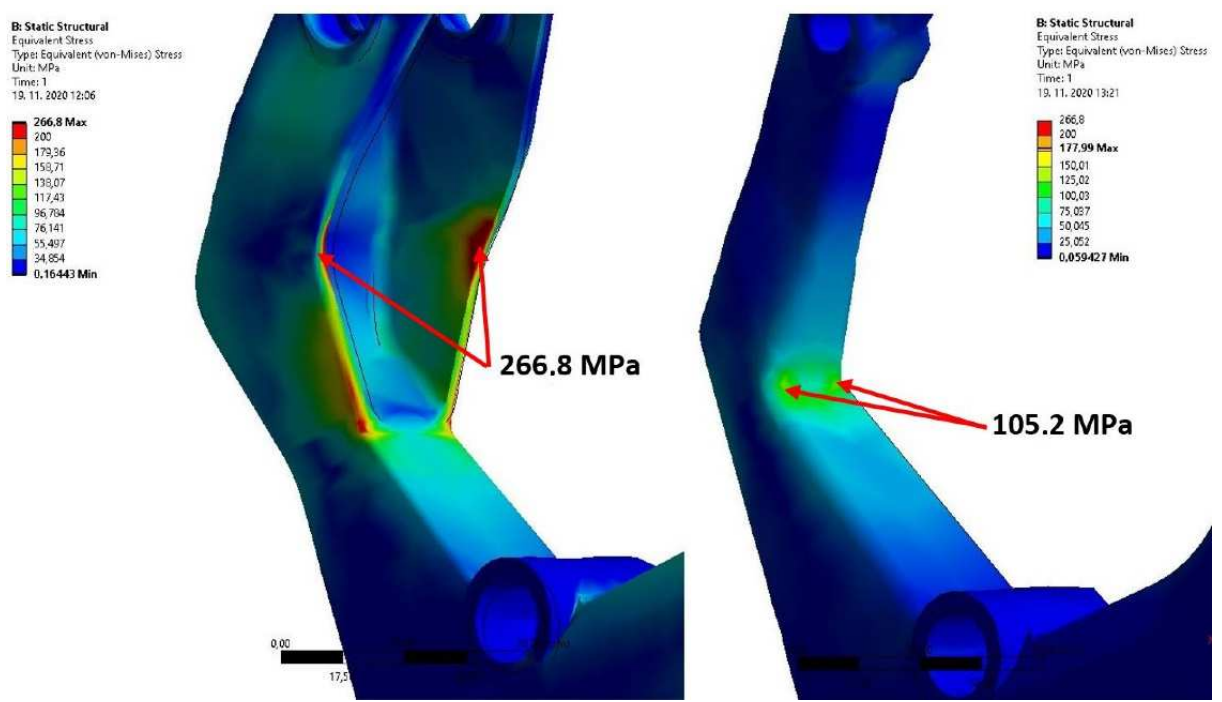

Figure 19. Comparison between original design and new-designed solution. 


\subsection{Frame Analysis during Pedalling off Saddle-Asymmetric Bending and Final Design}

It seems adequate to do suitable structural analysis with static and dynamic load according to previous chapters, where to load can be considered as "in-plane" load. The dynamic load can be defined via dynamic coefficient, in our case equal to, so dynamic load is three times higher than static load or via dynamic analysis (e.g., in ADAMS software). In-plane load corresponds to standard downhill scenarios when all forces (or their resulting force) act almost exclusively in the symmetry plane of the frame in order to maintain the stability of the "bicycle-rider" system. This is an example of riding on a saddle or out of the saddle, but the rider is standing statically evenly on both pedals (riding downhill with jumps under normal conditions).

However, there exist certain situations when the bicycle frame is loaded by a nonsymmetrical load, e.g., when a rider goes uphill during a race and is forced to pedal explosively, especially when pedalling of the saddle. In such a scenario, the rider is standing only on one pedal (concentrates the force on only one pedal, e.g., right) and pushing it down while pulling up the opposite handlebar grip (e.g., left, see Figure 20). The final resultant force applied to a pedal is then composed of the rider's weight and optionally additional reaction force derived by pulling the opposite handlebar grip. This causes an additional bending load acting out-of-the symmetry plane of the frame and thus leads to its lateral bending/twisting.

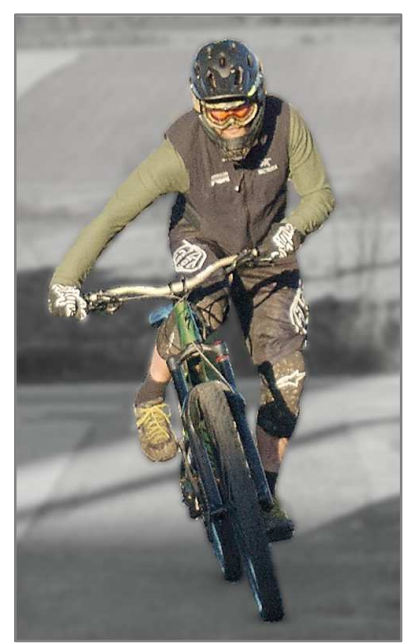

(a)

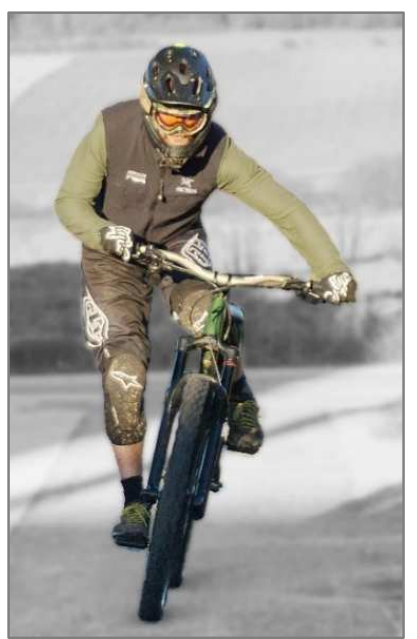

(b)

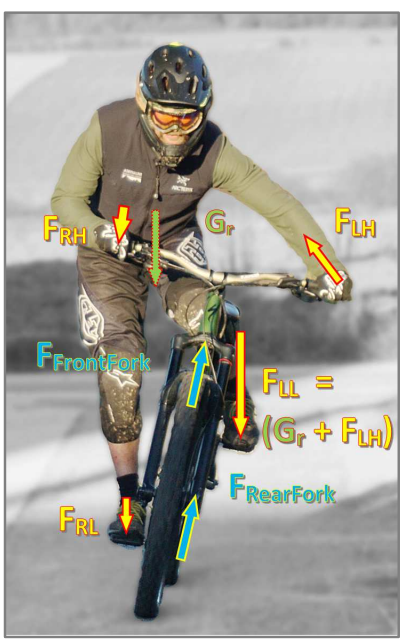

(c)

Figure 20. Rider's position while scenario "out of saddle pedalling" — front view with main acting forces in positions under maximum asymmetric loading: (a) position 1-rider starting to explosively push his right pedal down (standing on his right pedal) while simultaneously pull the left handlebar; (b) position 2-opposite situation; (c) main forces generating maximum asymmetric load in the frame.

Finally, we decided to carry out the additional analysis to verify these specific, and probably less favourable conditions as well. We decided to analyse the conditions (movements of the rider and the bicycle) by analysing the camera records of such a riding style in order to understand what movements they undertake and which forces and moments can act on individual parts of the bicycle frame during such a scenario. The time-lapse of our camera record is shown in figure Figure 20a,b where it is obvious that the rider's position is changing, as well as the bicycle position while off-saddle pedalling. Due to the difficulty of finding proper a mathematical model for its description, we will consider it with boundary conditions. In Figure 20c we can see a pedalling position in a situation where the rider is pushing via maximal force to the right pedal while his left foot is just placed on the left pedal. We can see the rider is not sitting on the saddle because he is pedalling much stronger compared to when he is sitting. While pedalling out of a saddle 
rider is holding a handlebar. There we can see also that the rider is pulling the opposite handlebar up with one hand and pushing the other handlebar with the other hand down.

For further calculation, we will specify the forces acting in the front frame triangle according to the boundary condition shown in Figure 21 (out of saddle pedalling). Forces $\mathrm{F}_{\mathrm{A}}$ and $\mathrm{F}_{\mathrm{C}}$ were described in the previous part, and force $\mathrm{F}_{\mathrm{H}}$ acting to headset and $\mathrm{F}_{\mathrm{B}}$ acting to the bottom bracket will be described below.

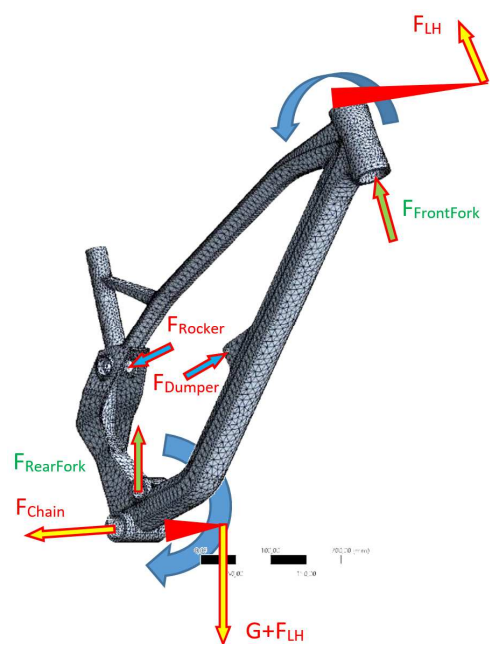

(a)

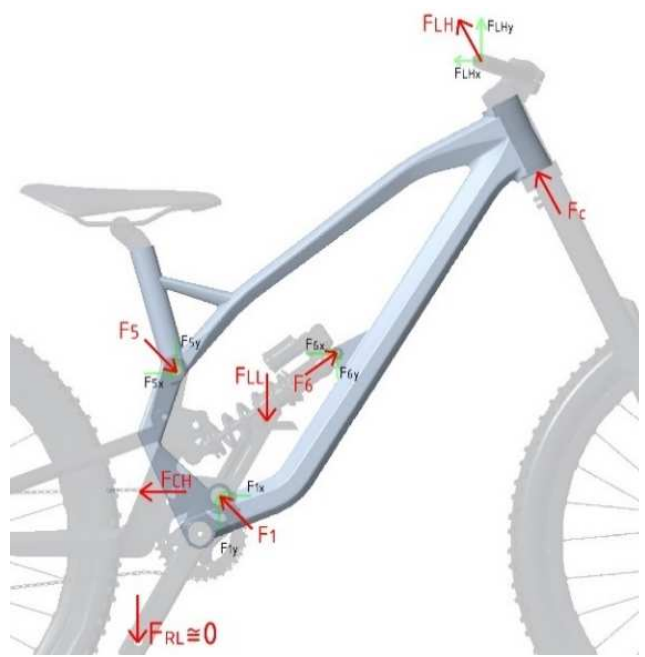

(b)

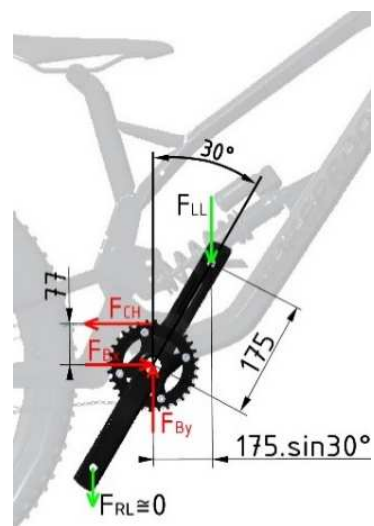

(c)

Figure 21. Forces acting in the front triangle during pedalling out of saddle, (a) schematic description in $3 \mathrm{D}$ view, (b) locations and directions of forces used in calculation and as input parameters in simulation software, (c) forces acting on pedals.

$\begin{array}{ll}\mathrm{F}_{\mathrm{RH}} & {[\mathrm{N}]} \\ \mathrm{F}_{\mathrm{A}} & {[\mathrm{N}]} \\ \mathrm{F}_{\mathrm{LH}} & {[\mathrm{N}]} \\ \mathrm{F}_{\mathrm{A}^{\prime}} & {[\mathrm{N}]} \\ \mathrm{F}_{\mathrm{RL}} & {[\mathrm{N}]} \\ \mathrm{F}_{\mathrm{B}} & {[\mathrm{N}]} \\ \mathrm{F}_{\mathrm{LL}} & {[\mathrm{N}]} \\ \mathrm{F}_{\mathrm{C}} & {[\mathrm{N}]} \\ \mathrm{F}_{\mathrm{G}} & {[\mathrm{N}]} \\ \mathrm{F}_{\mathrm{C}^{\prime}} & {[\mathrm{N}]} \\ \mathrm{F}_{\mathrm{H}} & {[\mathrm{N}]}\end{array}$

force made by right hand
force acting to rear wheel
force made by left hand
force to rear triangle made from $\mathrm{F}_{\mathrm{A}}$
force made by right leg
reduced force to bottom bracket
force made by left leg
force acting to front wheel
gravity force
force $\mathrm{F}_{\mathrm{C}}$ acting to bottom side of headset
force acting to upper side of head reduced from $\mathrm{F}_{\mathrm{RH}}$ and $\mathrm{F}_{\mathrm{LH}}$

For calculating out of plane/asymmetric bending during out of saddle pedalling we will need to know the reduced forces acting in the bottom bracket and headset. We consider that forces acting on other elements of the frame assembly are the same in comparison to the previous calculation.

Further, the forces $F_{B}$ and $F_{H}$ need to be calculated and specified. Bracket force $F_{B}$ comes from leg activity reduced to the bottom bracket. It can be considered that it is the same size as the gravity force but the acting plane is at an incline of $10^{\circ}$ with respect to the vertical plane (see Figure 20). The headset force $\mathrm{F}_{\mathrm{H}}$ is acting on headset and is defined as the hands' reaction to the handlebars. Its value can be set as $10 \%$ of the gravity force. The chain force $\mathrm{F}_{\mathrm{CH}}$ made by pedalling acting on the bottom bracket needs to be calculated as well and its calculation is shown below. The left leg force $F_{L L}$ is derived by the rider's left leg action and determined as a sum of the gravity force and the force made by the rider's hand when trying to rotate the bicycle to the opposite side during out of saddle pedalling. We consider the $\mathrm{F}_{\mathrm{LH}}$ value to be approximately $300 \mathrm{~N}$.

$$
F_{G}=1030 \mathrm{~N}, \quad F_{L H}=300 \mathrm{~N}
$$




$$
\begin{gathered}
F_{L L}=F_{G}+F_{L H} \\
F_{L L}=1330 \mathrm{~N} \\
\sum F_{i x}=0 ; \quad F_{B x}-F_{C H}=0 \rightarrow F_{C H}=F_{B x} \\
\sum F_{i y}=0 ; \quad F_{B y}-F_{L L}=0 \rightarrow F_{L L}=F_{B y} \\
\sum M_{i B}=0 ; \quad F_{C H} \cdot 77-F_{L L} \cdot 175 \cdot \sin 30^{\circ}=0 \\
F_{C H}=F_{L L} \cdot \frac{175 \cdot \sin 30^{\circ}}{77}=1468 \mathrm{~N}
\end{gathered}
$$

In the Figure 21a forces acting in the front triangle during out of saddle pedalling used for calculation are schematically shown. Like in the previous calculation as input parameters for the calculation, we choose all forces acting in the researched component, multiplied by a coefficient of size 1.5. The sizes of the forces used in the calculation are shown in Table 7, the location and directions of the resulting forces are shown in Figure 21b,c.

Table 7. Forces values used in structural analysis for case "off saddle pedalling".

\begin{tabular}{ccc}
\hline Force & Calculated Force $[\mathbf{N}]$ & Force Used in Analysis $[\mathbf{N}]$ \\
\hline $\mathrm{F}_{\mathrm{b}}[\mathrm{N}]$ & 1030 & 1545 \\
$\mathrm{~F}_{\mathrm{c}}[\mathrm{N}]$ & 372 & 558 \\
$\mathrm{~F}_{1 \mathrm{x}}[\mathrm{N}]$ & 3590 & 5385 \\
$\mathrm{~F}_{1 \mathrm{y}}[\mathrm{N}]$ & 1593 & 2390 \\
$\mathrm{~F}_{5 \mathrm{x}}[\mathrm{N}]$ & 1537 & 2306 \\
$\mathrm{~F}_{5 \mathrm{y}}[\mathrm{N}]$ & 2421 & 3632 \\
$\mathrm{~F}_{6 \mathrm{x}}[\mathrm{N}]$ & 2053 & 3080 \\
$\mathrm{~F}_{6 \mathrm{y}}[\mathrm{N}]$ & 1486 & 2229 \\
$\mathrm{~F}_{\mathrm{CH}}[\mathrm{N}]$ & 1468 & 2202 \\
$\mathrm{~F}_{\mathrm{LL}}[\mathrm{N}]$ & 1330 & 1995 \\
$\mathrm{~F}_{\mathrm{RL}}[\mathrm{N}]$ & $\cong 0$ & $\cong 0$ \\
$\mathrm{~F}_{\mathrm{LH}}[\mathrm{N}]$ & 300 & 450 \\
$\mathrm{~F}_{\mathrm{LHx}}[\mathrm{N}]$ & 140 & 210 \\
$\mathrm{~F}_{\mathrm{LHy}}[\mathrm{N}]$ & 264 & 396 \\
$\mathrm{~F}_{\mathrm{RH}}[\mathrm{N}]$ & $\cong 0$ & $\cong 0$ \\
\hline
\end{tabular}

The simulation output of the stress distribution within the frame still shows the highest stress level in the area of damage. In Figure 22a a detailed isometric view in comparison to the calculated stress field in the critical point of the original frame (Figure 22b) and redesigned frame (Figure 22c) is shown. The stress made in the researched place in the frame during pedalling out of the saddle is approximately the same size in comparison to our first stress analysis. In other parts of the frame, the stress is higher due to frame twisting and tube bending. We can also see increased tension on the top and bottom tube because of the frame bending which is caused by frame tilt and pedalling. The size of the highest tension in the top and bottom tube is $117.44 \mathrm{MPa}$ which is located on the weld between the top tube and headtube. The yield strength of $\mathrm{Al} 6061-\mathrm{T} 6$ is $\mathrm{Re}=276 \mathrm{MPa}$. The resulting tension value is less than the yield strength of the Al 6061-T6. The size of increased tensions depends on the tilt of the bicycle and on the size of the forces generated by the rider's legs while pedalling. 


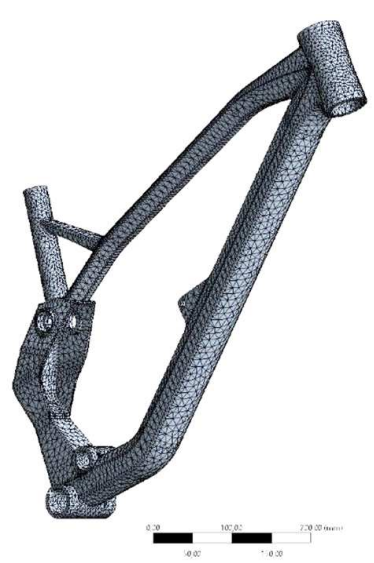

(a)

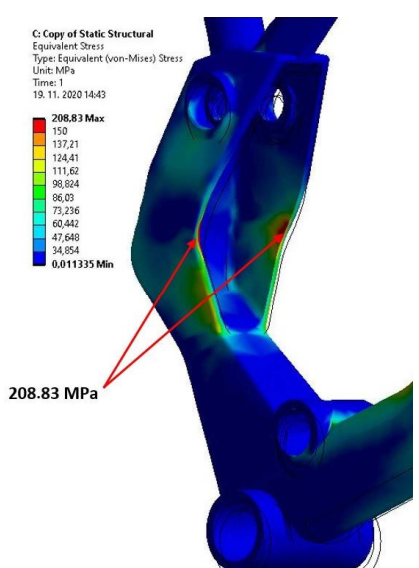

(b)

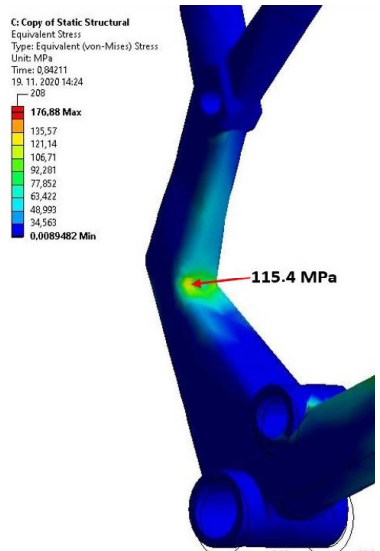

(c)

Figure 22. The results of the static structural analysis calculation during out of saddle pedallingcomparison of old and new design-detailed view on critical point: (a) meshing for FEM analysis on old design; (b) stress maximum in old design with pocket tube element; (c) stress maximum in new design with connection of two pipes at an angle.

In Figure 23 a graphical output of the researched place in the improved redesigned frame is shown. It can be seen that the stress level during out of saddle pedalling is 105.4 MPA, which is twice as high as normal symmetrical loading which was $54.70 \mathrm{MPa}$. The stress made during standing pedalling is significantly smaller than in the case of the old design as well as smaller than the yield strength of Al 6061-T6.

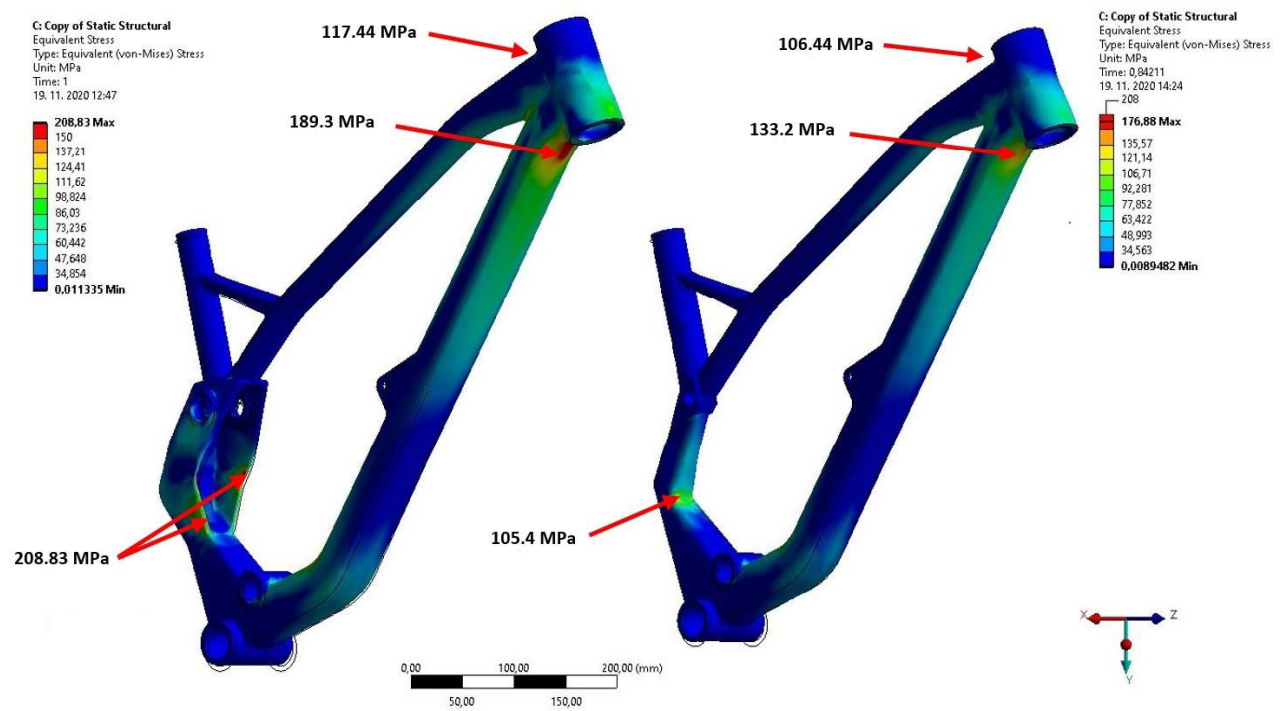

(a)

(b)

Figure 23. The results of static structural analysis calculation during out of saddle pedallingcomparison of old and new design: (a) old design with pocket tube element; (b) new design with connection of two pipes at an angle.

Final render of chosen conceptual design-using the CAD software Creo Parametric 2.0 a completed 3D model of the improved redesigned bicycle frame was created shown in Figure 24. In Figure 24b a detailed view of the designed linkage is shown. Figure 25 shows the final render in the designed color and the complete bike after the production and assembling. 


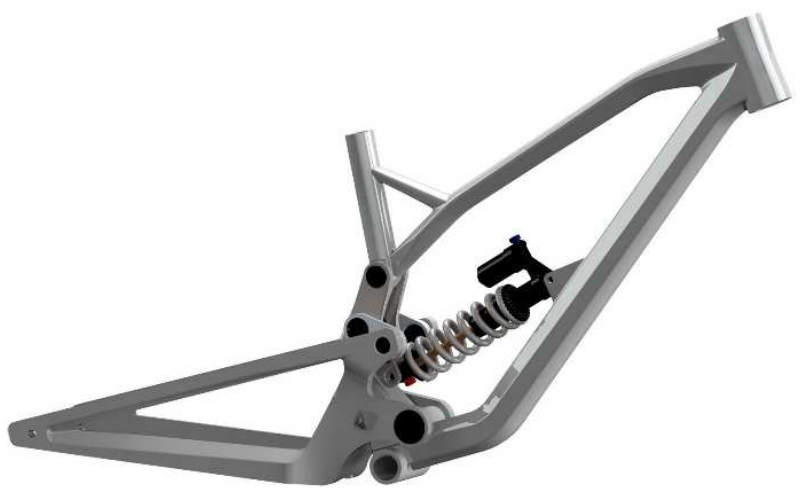

(a)

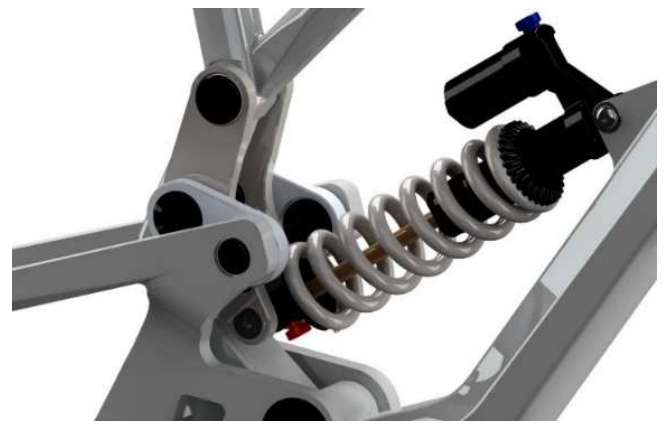

(b)

Figure 24. Complete CAD model of designed solution (a); detailed view of linkage used in designed solution (b).

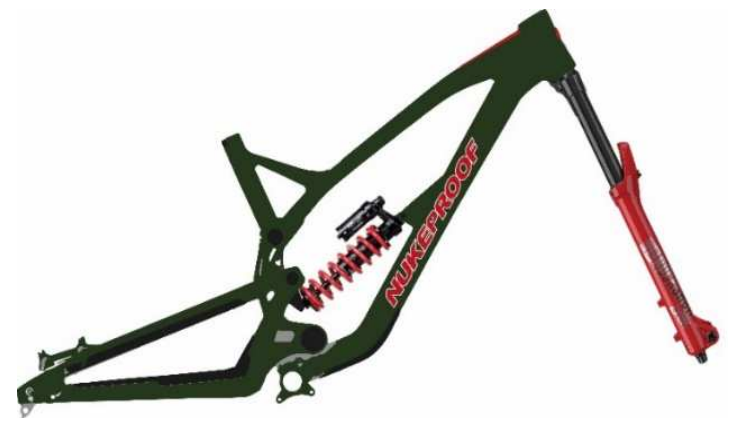

(a)

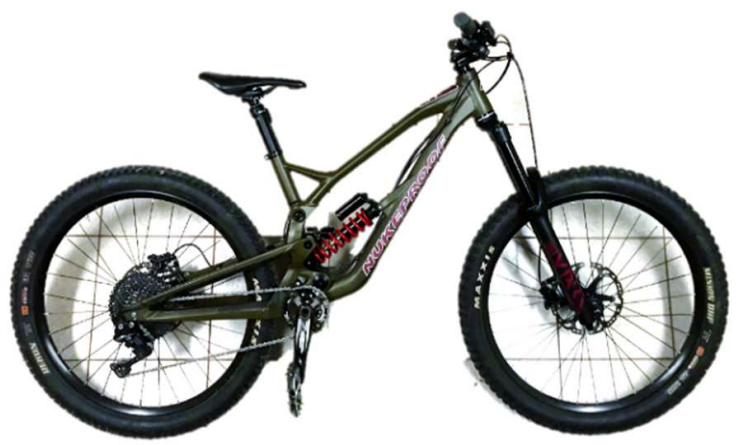

(b)

Figure 25. Final render of frame in designed color (a); complete bike assembly (b).

\section{Discussion}

In the beginning, the precise CAD model of the original bicycle frame was created and analysed in ANSYS/Workbench software. The results of the provided FEM analysis show that there is a weak or critical point of the original frame design where the stress is concentrated, and the values exceed the material capability. This point is located in the "pocket arms" of the advanced shape vertical tube under the seat where the rear triangle to the linkage element is connected. So, the main reason for the frame failure and crack was confirmed via simulation as well. The static structural simulation performed in ANSYS/Workbench shows that there is a significant increase in tension in the researched area when the bicycle is loaded. The local stress level is several times higher (maximum is 237.36 MPa) than in other places of the front frame triangle. The yield strength of material Al 6061-T6 is $R_{e}=276 \mathrm{MPa}$, so the resulting tension values are still less than the yield strength of the used material. However, due to the previously mentioned disproportion as well the usage of bicycles downhill in rough terrain, this location can be identified as a significantly critical point of the whole bicycle. Therefore, it is obvious why the cracks were initialized in such a location, and the frame design should be improved.

Based on these results, two basic design concepts were proposed: application of pocket with increased wall thickness and pocket structure replacement by tube segments welded into the original frame. The second alternative was considered more suitable. In the chosen design, a multiple tension reduction in the resulting stresses from the original $\sigma_{\max }=208.83 \mathrm{MPa}$ to the current $\sigma_{\max }=105.4 \mathrm{MPa}$ was observed, compared to the original design. Based on these numbers, we can assume that the newly proposed design can be successfully implemented due to the final reduction of maximum stress levels in the researched place approximately two times (only $50.4 \%$ of original stress maximum) than 
the original pocket design and can therefore bring a much lower risk of frame failure in the future during the bicycle usage.

In the end, we can conclude that the importance of the precise study of a proposed mechanical design, including the calculation of generated forces in each structural element, as well as the role of FEM analysis, is rapidly increasing in the bicycle industry mainly due to the increasing complexity, and application of innovative but advanced shape designs of bicycle frames and each component. At the same time, it is clear that the engineering phase can dramatically reduce future costs and can help to avoid any other comprehensive warranty repairs for customers.

Based on our analysis, we can conclude that the major effect on frame sizing and proper shape finding in general cases was the symmetrical dynamic load while jumping. However, asymmetrical loading (out of plane bending) which occurs while the rider is pedalling out of the seat can reach very important or critical roles in cases of frame features designed as cavity or pocket shape. In such cases, the pocket ribs can lead to stress concentration and in the worst cases can end with cracks. In view of our findings, we can confirm that in the case of bicycle frames with the expected high asymmetric bending load (also the example of racing full suspension bicycles) it is more appropriate to adhere to the use of conventional tubular profiles in critical parts of the frame, which better distribute stress.

Finally, we consider it necessary (to avoid taking our contribution as a negative advertisement) to point out that the bike manufacturer has changed the original design of the frame. The new model of Nukeproof's full suspension downhill bike Dissent (placed on the market 2020) contains a similar solution for analysed detail.

\section{Conclusions}

The strength and stiffness of the frame components are some of the key indicators of all vehicles. Insufficient stiffness can cause vibration, noise or can lead to structural failure in extreme cases. The presented case study deals with the analysis and improvement of a critical point of a main frame for the full suspension bicycle, Nukeproof Pulse Pro (version 2018) via FEM analysis. It shows the individual phases of the engineering process from the analysis of original design, identification of the weak point, proposal of a new solution, up to the final validation and implementation into the selected bicycle. Initial simulations did not indicate that any possible design failure due to use could occur at that point. Only a more detailed analysis of driving scenarios identified the conditions leading to that situation. The effects of the symmetrical and asymmetrical way of bicycle loading in individual driving modes on the possible stress concentration and their contribution to the crack formation were investigated in more detail in the present study. Based on the simulation results, the asymmetrical combined stress of the bicycle main frame during an explosive aggressive ride out of the saddle proved to be critical, and the side arms of the pocket under the saddle tube were identified as a critical point. The effort to repair the author's bicycle after the real damage as well as understanding the cause of failure of a particular frame detail and the way it can be solved properly can be considered as the main motivations of the presented case study. As future work, we would like to test a modified bicycle frame in the field in order to check the effect of the modification on driving performance. We have an idea to implement the set of different sensors (tensiometers, accelerometers, etc.) on a testing bicycle to verify the simulation data in real conditions. However, the modified frame is not finished yet.

Author Contributions: Conceptualization, V.B. and I.K.; methodology, M.S. and S.L.; software, M.B. and M.V.; validation, Z.S. and M.V., resources, M.B.; writing-original draft preparation, M.B. and V.B.; writing-review and editing, Z.S., S.L. and M.S.; visualization, M.B. and V.B.; supervision, I.K. and S.L.; project administration, M.S.; funding acquisition, I.K. All authors have read and agreed to the published version of the manuscript.

Funding: This research was funded by APVV, grant number APVV-17-0310. Project title: Implementation of the 4th Industrial Revolution Principles in the Production of Tyre Components and project 
VEGA 1/0864/21. The APC was funded by VEGA 1/0864/21 and UNIZA grant system: Application of geometric specification in the evaluation process of intelligent production systems (12729).

Institutional Review Board Statement: Not applicable.

Informed Consent Statement: Not applicable.

Data Availability Statement: Data is contained within the article or on request from the corresponding author.

Conflicts of Interest: The authors declare no conflict of interest. The funders had no role in the design of the study; in the collection, analyses, or interpretation of data; in the writing of the manuscript, or in the decision to publish the results.

\section{References}

1. Atkinson, G.; Davison, R.; Jeukendrup, A.; Passfield, L. Science and cycling: Current knowledge and future directions for research. J. Sports Sci. 2003, 21, 767-787. [CrossRef]

2. Bartoš, M. Proposal for the Modification of the Critical Point on the Frame of the Downhill Bike. Master's Thesis, University of Žilina, Žilina, Slovakia, 2019. (In Slovak).

3. Macdermid, P.W.; Fink, P.W.; Miller, M.C.; Stannard, S. The impact of uphill cycling and bicycle suspension on downhill performance during cross-country mountain biking. J. Sports Sci. 2017, 35, 1355-1363. [CrossRef]

4. Cheng, Y.-C.; Lee, C.-K.; Pornteparak, P. An improved design of an on-road bicycle frame under fatigue testing simulations. J. Chin. Inst. Eng. 2020, 43, 2158-7299. [CrossRef]

5. Xiao, D.; Liu, X.; Du, W.; Wang, J.; He, T. Application of topology optimization to design an electric bicycle main frame. Structural and Multidisc. Optimization 2012, 46, 913-929. [CrossRef]

6. Liu, Y.-S.; Tsay, T.-S.; Wang, T.-C.; Liu, C.-F. Analyzing the influences of bicycle suspension systems on pedaling forces and human body vibration. J. Vibroeng. 2014, 16, 2527-2535.

7. Maier, O.; Gyorfi, B.; Wrede, J.; Kasper, R. Design and validation of a multi-body model of a front suspension bicycle and a passive rider for braking dynamics investigations. Multibody Syst. Dyn. 2018, 42, 19-45. [CrossRef]

8. Cicero, S.; Lacalle, R.; Cicero, R.; Fernández, D.; Méndez, D. Analysis of the cracking causes in an aluminium alloy bike frame. Eng. Fail. Anal. 2011, 18, 36-46. [CrossRef]

9. Covill, D.; Begg, S.; Elton, E.; Milne, M.; Morris, R.; Katz, T. Parametric Finite Element Analysis of Bicycle Frame Geometries Procedia Eng. 2014, 72, 441-446. [CrossRef]

10. Covill, D.; Allard, P.; Allard, P.; Drouet, J.M.; Emerson, N. An Assessment of Bicycle Frame Behaviour under Various Load Conditions Using Numerical Simulations. Procedia Eng. 2016, 147, 665-670. [CrossRef]

11. Gupta, R.; Rao, G.V.R.S. Analysis of Mountain Bike Frame by FEM. IOSR J. Mech. Civ. Eng. 2016, 13, 60-71. [CrossRef]

12. Liu, X.; Shi, G. Residual stress detection of welded parts based on excitation vibration response. Int. J. Adv. Robot. Syst. 2020, 17, 1-11. [CrossRef]

13. Virgala, I.; Kelemen, M.; Božek, P.; Bobovský, Z.; Hagara, M.; Prada, E.; Oščádal, P.; Varga, M. Investigation of Snake Robot Locomotion Possibilities in a Pipe. Symmetry 2020, 12, 939. [CrossRef]

14. Kelemen, M.; Virgala, I.; Lipták, T.; Miková, L'; Filakovský, F.; Bulej, V. A Novel Approach for A Inverse Kinematics Solution of a Redundant Manipulator. Appl. Sci. 2018, 8, 2229. [CrossRef]

15. Redfield, R. Large motion mountain biking dynamics. Veh. Syst. Dyn. 2005, 43, 845-865. [CrossRef]

16. Kopas, P.; Blatnický, M.; Sága, M.; Vaško, M. Identification of mechanical properties of weld joints of AlMgSi07.F25 aluminium alloy. Metalurgija 2017, 56, 99-102.

17. Vaško, A.; Belan, J. Fatigue tests of nodular cast iron at low and high frequency cyclic loading. Mater. Today Proc. 2017, 4, 5985-5988. [CrossRef]

18. Chacon-Murguia, M.I.; Sandoval-Rodriguez, R.; Arias-Enriquez, O. Human Gait Feature Extraction Including a Kinematic Analysis toward Robotic Power Assistance. Int. J. Adv. Robot. Syst. 2012, 9, 1-9. [CrossRef]

19. Mellion, M.B. Common Cycling Injuries. Sports Med. 1991, 11, 52-70. [CrossRef] [PubMed]

20. Ptak, M.; Wilhelm, J.; Sawicki, M.; Rusinski, E. Child safety on various bicycle-mounted seats during vehicle impact. Transport 2019, 34, 684-691. [CrossRef]

21. Zuraulis, V.; Levulyte, L.; Sokolovskij, E. The impact of road roughness on the duration of contact between a vehicle wheel and road surface. Transport 2014, 29, 431-439. [CrossRef]

22. Bárnik, F.; Vaško, M.; Sága, M.; Handrik, M.; Sapietová, A. Mechanical properties of structures produced by 3D printing from composite materials. MATEC Web Conf. 2019, 254, 01018. [CrossRef]

23. Sniehotta, P. 3D printed belt wheels for use in design of bicycles. MM Sci. J. 2020, 13, 3813-3817. [CrossRef]

24. Perfetto, D.; Lamanna, G.; Sepe, R.; De Luca, A. Design of a Bamboo Treadmill Bicycle Main Frame. Macromol. Symp. 2020, 389, 1900101. [CrossRef]

25. Lin, H.-C.; Yu, B.-R.; Wang, J.-Y.; Lai, J.-Z.; Wu, J.Y. Achievement of Accurate Robotic Arm-based Bike Frame Quality Check Using 3D Geometry Mathematical Model. Appl. Sci. 2019, 9, 5355. [CrossRef] 
26. Yang, H.T.; Kwon, I.Y.; Randall, C.J.; Hansma, P.K.; Ly, F.S. Preliminary design, experiment, and numerical study of a prototype hydraulic bio-inspired damper. J. Sound Vib. 2019, 459, 114845. [CrossRef]

27. Nukeproof-Pulse Pro. Available online: http://nukeproof.com/products/pulse/ (accessed on 11 February 2019).

28. MTBIKER - Short Cycling Dictionary: Frame Geometry and in-Depth Explanation of Terms. Available online: https://www. mtbiker.sk/clanky/8807/kratky-cyklisticky-slovnik-geometria-ramu-a-hlbkovy-vyklad-pojmov.html (accessed on 21 March 2019). (In Slovak).

29. MTBIKER — Comparison of Materials for Frame Construction—Properties, Advantages, Disadvantages and Their Use. Available online: https:/ / www.mtbiker.sk/clanky/9471/porovnanie-materialov-na-stavbu-ramu-vlastnosti-vyhody-nevyhody-aichvyuzitie.html (accessed on 30 March 2019). (In Slovak).

30. Nedal Aluminium 2005-EN AW-6061. Alloy Datasheet: EN AW-6061 [AlMg1SiCu]. Available online: http://www. nedalextrusion.com/files/9613/0678/5550/Data_6061.pdf (accessed on 18 April 2019).

31. Material Properties Data: 6061-T6 Aluminum, ASM Material Data Sheet Johnson Centrifugal—Aluminum Alloys. Available online: http:/ /johnsoncentrifugal.com (accessed on 16 April 2019).

32. 6061 Aluminium Alloy. Available online: https://en.wikipedia.org/wiki/6061_aluminium_alloy (accessed on 19 April 2019).

33. ALUNET-Alunet EN AW-6082 T6 (AlMgSi1 F28/F31/F32). Available online: http:/ / www.alunet.cz/ENAW-6082 (accessed on 7 May 2019).

34. AGMETAL-Conversion Tables of Material Qualities and Properties of Steels. Available online: http://www.agmetall.cz/cs / jakosti-materialu-a-vlastnosti-oceli (accessed on 5 March 2019). (In Czech). 